\title{
RESEARCH
}

\section{The effect of absent blood flow on the zebrafish cerebral and trunk vasculature}

\author{
Elisabeth Kugler ${ }^{(1)}$,2,3,4, Ryan Snodgrass1,2, George Bowley1,2, Karen Plant 1,2, Jovana Serbanovic-Canic ${ }^{1,2}$, \\ Noémie Hamilton1,2, Paul C Evans 1,2,3, Timothy Chico (D1,2 and Paul Armitage 1,3 \\ 'Department of Infection, Immunity and Cardiovascular Disease, University of Sheffield, Medical School, Sheffield, UK \\ 2The Bateson Centre, Firth Court, University of Sheffield, Western Bank, Sheffield, UK \\ Insigneo Institute for in silico Medicine, Sheffield, UK \\ 4Institute of Ophthalmology, Faculty of Brain Sciences, University College London, London, UK
}

Correspondence should be addressed to E Kugler: e.kugler@ucl.ac.uk

\begin{abstract}
The role of blood flow in vascular development is complex and context-dependent. In this study, we quantify the effect of the lack of blood flow on embryonic vascular development on two vascular beds, namely the cerebral and trunk vasculature in zebrafish. We perform this by analysing vascular topology, endothelial cell (EC) number, EC distribution, apoptosis, and inflammatory response in animals with normal blood flow or absent blood flow. We find that absent blood flow reduced vascular area and EC number significantly in both examined vascular beds, but the effect is more severe in the cerebral vasculature, and severity increases over time. Absent blood flow leads to an increase in non-EC-specific apoptosis without increasing tissue inflammation, as quantified by cerebral immune cell numbers and nitric oxide. Similarly, while stereotypic vascular patterning in the trunk is maintained, intra-cerebral vessels show altered patterning, which is likely to be due to vessels failing to initiate effective fusion and anastomosis rather than sprouting or pathseeking. In conclusion, blood flow is essential for cellular survival in both the trunk and cerebral vasculature, but particularly intra-cerebral vessels are affected by the lack of blood flow, suggesting that responses to blood flow differ between these two vascular beds.
- in vivo
- light sheet
- quantification
- vasculature
- zebrafish

Key Words
\end{abstract}

\section{Introduction}

Endothelial cells (ECs) perform multiple functions during normal physiology including wound healing, tissue regeneration, immune response, menstruation, and pregnancy $(1,2,3)$. Cerebral EC dysfunction is associated with neurodegenerative diseases, arteriovenous malformations, aneurysms, and stroke $(4,5)$. Increasing evidence suggests ECs display different molecular and functional properties according to their anatomical site, such as the cerebral or trunk vessels $(6,7,8,9,10)$. This highlights the importance of studying the responses of multiple vascular in development and territories to experimental manipulations.

Zebrafish embryos are a frequently used model to study vascular development and disease $(11,12,13)$. Fluorescent transgenic reporter lines allow cellular and sub-cellular visualization in vivo (14). Advanced microscopy, such as light sheet fluorescence microscopy (LSFM), acquires vascular information in great anatomical depth and over prolonged periods of time (15), allowing data acquisition to be rich in information and detail. Zebrafish embryonic (c) 2021 The authors Published by Bioscientifica Ltd 
transparency allows non-invasive and in vivo studies of different vascular beds in the same animal.

After $24 \mathrm{~h}$ post-fertilization (hpf), the zebrafish basic body plan is established and cardiac contraction starts. Within this timeframe, vasculogenesis forms the primary vessels $(16,17)$. Blood flow plays an important role in processes, such as EC polarization, vascular lumenization, pruning, and cardiac trabeculation $(18,19,20,21,22$, $23,24)$, and directly impacts vascular architecture (25). Zebrafish embryos can survive for 7 days post fertilization (dpf) without blood flow via oxygen diffusion due to their small size $(13,26)$. This makes them well suited to examine the role of blood flow on vasculogenesis and angiogenesis.

One approach to study the effect of absent blood flow in zebrafish is the knockdown of cardiac troponin T2A (tnnt2a) using antisense morpholino oligonucleotides (MO). This prevents cardiac contraction and thus blood flow $(27,28)$. Contrary to recent debates on $\mathrm{MO}$ phenocopying mutant phenotypes, the tnnt2a MO phenocopies thesilentheart(sih) mutation (28), making it a widely used MO-based approach to study the lack of blood flow. Additionally, a control MO group accounts for injection-induced developmental delays (29). Previous studies used this MO-based method to study the impact of blood flow on specific cerebral $(30,31)$ and trunk vessels (32), showing that EC numbers are reduced in the trunk when blood flow is absent $(32,33)$.

Even though these studies have provided invaluable insights into the role of blood flow, important questions remain unanswered about the role of blood flow in vascular development. These include whether absent blood flow has the same effects in different vascular beds, whether vessels of different identities respond differently, which steps of vasculature formation are altered, and whether effect sizes of absent blood flow differ in magnitude over time.

To examine these questions. we here use LSFM 3D in vivo imaging of the cerebral and trunk vasculature of 2-5dpf zebrafish embryos with and without blood flow induced by tnnt $2 a$ knockdown. Our results show that even though the gross vascular responses to blood flow are comparable in different territories, some differences between anatomical sites exist, suggesting vascular territories exhibit differential sensitivity to absent blood flow.

\section{Materials and methods}

\section{Zebrafish husbandry}

Experiments were performed according to the rules and guidelines of institutional and UK Home Office regulations under the Home Office Project Licence 70/8588 held by TC.

Maintenance of adult zebrafish was performed as described in standard husbandry protocols $(34,35)$. Embryos, obtained from controlled mating, were kept in E3 $(5 \mathrm{mM} \mathrm{NaCl}, 0.17 \mathrm{mM} \mathrm{KCl}, 0.33 \mathrm{mM} \mathrm{CaCl} 2,0.33 \mathrm{mM}$ $\mathrm{MgSO}_{4}$ ) medium buffer with methylene blue and staged according to Kimmel et al. (36). The following transgenic reporter lines were used: $T g(k d r l: H R A S-m C h e r r y) s 916$ (37) visualizes EC membrane, $\operatorname{Tg}($ fli1a:eGFP)y1 (14) visualizes EC cytosol, $\operatorname{Tg}(f l k 1: n l s-e G F P)$ zf109 (38) visualizes EC nuclei, $\operatorname{Tg}(m p x: G F P)^{i 114}$ (39) visualizes neutrophils, and Tg(fms:GAL4.VP16)i186, Tg(UAS-E1b:nfsB.mCherry)il149 (40) visualizes macrophages. To assess cell death in vivo, we created the stable transgenic $\mathrm{Tg}\left(\sec\right.$ AnnexinV:mVenus) ${ }^{5 H 632}$ in pDestCryaa:RFP, similar to (41) and the plasmid cloning of (42).

\section{Morpholino injection}

Development of functional heart contraction was inhibited via injection of tnnt2a ATG morpholino (1.56 ng final concentration), as described in $(27,28)$ (sequence 5'-CATGTTTGCTCT GATCTGACACGCA-3'). Control morpholino injections (5'-CCTCTTACCTCAGTTATTTATA-3'; no target sequence and little/no biological activity; Genetools, LLC) were performed with the above final concentration to study offtarget effects of injections. Injections were conducted at a one-cell stage using phenol red as an injection tracer.

\section{Chemical and histological stains}

In vivo visualization of cell death was performed using $2 \mu \mathrm{g} / \mathrm{mL}$ solution of Acridine Orange (Sigma) in 1X E3 for $2 \mathrm{~h}$ in 3dpf embryos, followed by three washes in E3 before image acquisition (43).

In vivo visualization of inflammation via nitric oxide (NO) (44) was performed using $2.5 \mu \mathrm{M}$ DAF-FM-DA (Molecular Probes; D23844) (45) for $6 \mathrm{~h}$ in 3dpf embryos. DMSO control was performed at the same concentration and duration.

\section{Image acquisition settings and properties}

Anaesthetized embryos were embedded in 2\% LMPagarose with 0.01\% Tricaine in E3 (MS-222, Sigma). Data acquisition of the cranial and trunk vasculature was performed using a Zeiss Z.1 light sheet microscope, PlanApochromat $20 \times / 1.0$ Corr nd $=1.38$ objective, dual-side

This work is licensed under a Creative Commons Attribution-NonCommercial 4.0 International License. 
illumination with online fusion, activated Pivot Scan, image acquisition chamber incubation at $28^{\circ} \mathrm{C}$, and a scientific complementary metal-oxide-semiconductor (sCMOS) detection unit. The properties of acquired data were as follows: 16 bit image depth, $1920 \times 1920 \times 400-600$ voxel (x,y,z; approximate voxel size of $0.33 \times 0.33 \times 0.5 \mu \mathrm{m}$, respectively). Multicolour images in double-transgenic embryos were acquired in sequential mode.

\section{Image analysis}

As tnnt $2 a$ can develop considerable oedema, we ensured comparability between samples by standardized image acquisition from the dorsal view, including the most dorsal vessel the dorsal longitudinal vein (DLV) to the more ventral basilar artery (BA; Supplementary Fig. 3A, see section on supplementary materials given at the end of this article). For image analysis, ROI selection was performed as previously described (Supplementary Fig. 9B) (46).

\section{Automatic nuclei detection}

To remove salt-and-pepper noise (47), a 6-by-6 neighbourhood median filter (48) was applied, while background removal was achieved with the rolling ball algorithm with size 200 (49). Following, 2D maximum intensity projection, and detection of local noise maxima using Fiji Software $(50,51)$. The Voronoi diagram was established following Otsu thresholding (52). Nuclei nearest neighbour distance (NND) was quantified in MIPs following pre-processing as above and Otsu thresholding, using the Fiji NND plugin (https://icme.hpc.msstate. edu/mediawiki/index.php/Nearest_Neighbor_Distances_ Calculation_with_ImageJ.html).

\section{Signal intensities}

Signal intensity measurement of Acridine Orange and DAF-FM was conducted by creating 3D vascular masks following Sato filter for vascular enhancement and Otsu thresholding segmentation as previously described (46, $53,54)$. Signal mean was quantified in ROIs in 2D MIPs. The signal-to-noise (SNR) ratio was quantified as the mean signal in ROI divided by the mean signal of the background (ROI placed outside the fish with a size of $10 \times 10 \mu \mathrm{m}$ ). Acridine orange foci were detected in ROI following $2 \mathrm{D}$ median filtering using the detection of maxima with intensity over 10 .

\section{Manual analysis}

All analysis was performed using Fiji (51).
Diameter of basilar artery (BA) was measured approximately $30 \mu \mathrm{m}$ before bifurcating into posterior (caudal) communicating segments (PCS).

Posterior cerebral vein $(\mathrm{PCeV})$ was measured approximately $20 \mu \mathrm{m}$ before turning dorsally.

Posterior cardinal vein (PCV) and dorsal aorta (DA) diameters were measured above the cloaca, with three measurement points each in the same animal.

Intersegmental vessel (ISV) lengths of arterial (aISVs) and venous (vISVs) were measured above the cloaca, with three measurement points of the same vessels each in the same animal.

Vessel-specific nuclei measurements were conducted manually. First, nuclei were counted in aISVs and vISVs closest to the cloaca. Secondly, nuclei in the PCeV and BA were measured in an $80 \mu \mathrm{m}$ long ROI positioned from the posterior end of the PCeV.

CtA sprouting and connectivity to BA were measured manually from the left PHBC.

\section{Immune cells}

Intracranial macrophages and neutrophils were quantified manually in 3D after ROI selection of the dorsal cerebral vasculature.

\section{Availability of data and the code}

Data and code will be made available upon request.

\section{Statistical analysis}

Gaussian distribution conformation was evaluated using the D'Agostino-Pearson omnibus test (21). Statistical analysis was performed using one-way ANOVA or paired Students t-test in GraphPad Prism Version 7 (GraphPad Software). Statistical significance was represented as: ${ }^{*} P<0.05,{ }^{* *} P<0.01,{ }^{* * *} P<0.001,{ }^{* * * *} P<0.0001$. Graphs show mean values \pm S.D. unless otherwise indicated. Image representation and visualization were done with Inkscape Version 0.48 (https://www.inkscape.org). Images were visualized as maximum intensity projections (MIPs). 3D rendering was performed using Arivis software (arivis AG, Munich, Germany).

\section{Results}

Cerebrovascular patterning is impaired by absent blood flow

We first examined whether cerebrovascular patterning is altered by lack of blood flow. Thus, we compared the

This work is licensed under a Creative Commons Attribution-NonCommercial 4.0 International License. 
cerebral vascular morphology of uninjected controls (Fig. 1A, B, C and D), control MO (Fig. 1E, F, G and H), and tnnt $2 a$ MO-injected embryos (Fig. 1I, J, K and L). When examining the global morphology, tnnt $2 a \mathrm{MO}$ showed pericardial oedema, eye oedema, smaller eyes, and abnormal body curvature, which became more severe over time (Supplementary Fig. 1). The tnnt $2 a$ morphants were smaller with overtly abnormal cerebral vasculature, with effects becoming more severe from 2 to $5 \mathrm{dpf}$. Intracerebral vessels, especially in the midbrain, were most severely affected showing altered growth patterns and an overall reduction of cerebral size was observed (Fig. 1L, dotted line). The primary head sinus (PHS), which extends laterally to the otic vesicle (OV), was enlarged,

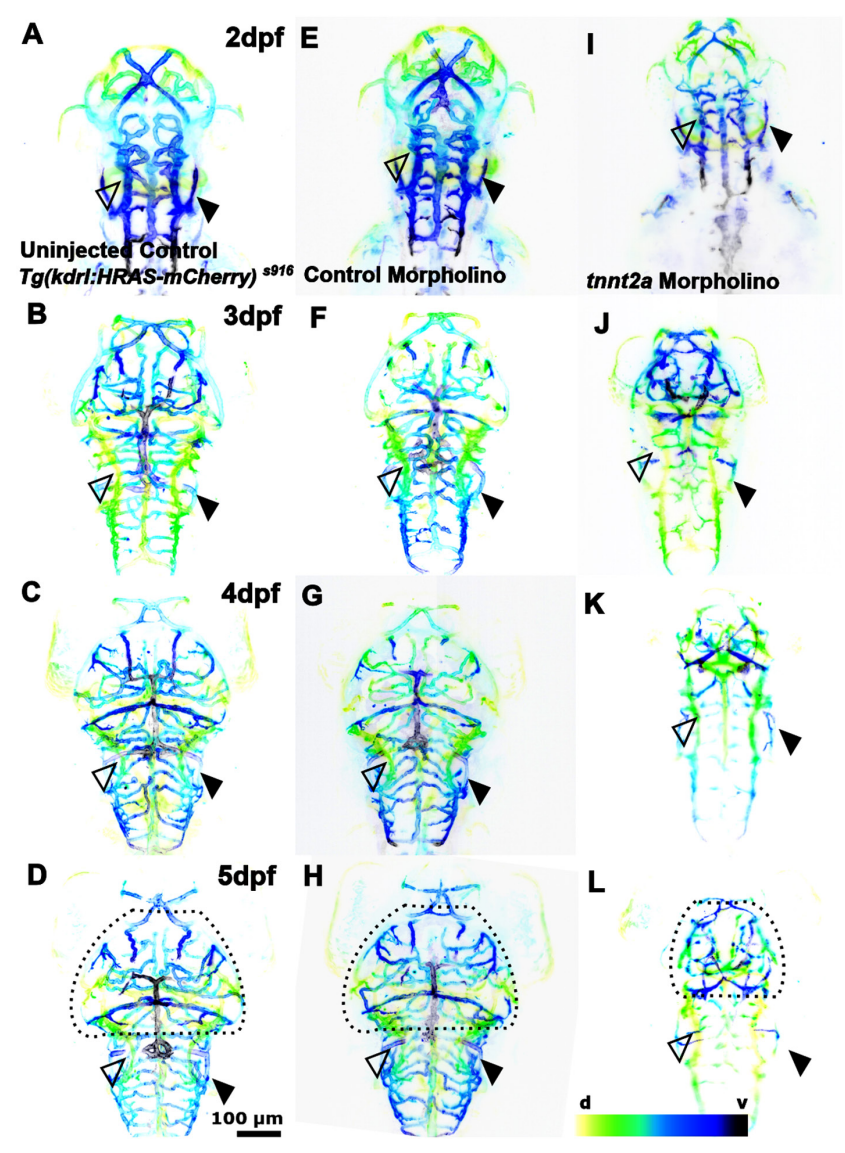

Figure 1

The effect of tnnt2a morpholino knockdown on cerebral vessel development. (A, B, C and D) Cerebral vasculature from 2 to $5 \mathrm{dpf}$ in Tg(kdrl:HRAS-mCherry)s916 uninjected animals. (E, F, G and H) Cerebral vasculature in control MO-injected animals. (I, J, K and L) Cerebral vasculature in tnnt2a MO injected animals ( $n=7-10$; two experimental repeats). The lack of blood flow in tnnt2a morphants perturbs vascular development and worsens over time. Comparison between treatment groups shows that the midbrain vasculature is severely affected in tnnt2a MO (dotted lines) and the PCV surrounding the OV is enlarged (filled arrowhead), while the PHBC appears normal (unfilled arrowhead; $\mathrm{d}$ - dorsal, v - ventral; representative images colour-coded by depth). suggesting OV enlargement (Fig. 1L, filled arrowheads), while peripheral/perineural vessels, such as the primordial hindbrain channel (PHBC), formed relatively normally (Fig. 1L, unfilled arrowhead; schematic of cerebral vessels from 2 to 5 dpf Supplementary Fig. 2). Our observations also confirm previous work in which vessels from the spinal cord and brain are still undergoing integration in the absence of blood flow (55).

We next examined the distribution of EC in these animals (Fig. 2). This also suggested that peripheral vessels were less severely affected by absent blood flow, for example, when comparing nuclei distribution in the middle cerebral vein (MCeV, Fig. 2, unfilled arrowhead) to central arteries (Fig. 2, black arrowhead). This was confirmed when examining Voronoi diagrams of EC nuclei distribution (Fig. 2M, N and O). Voronoi tessellation, overlapping nuclei images, aided the visualization of EC nuclei density/ distribution by partitioning MIPs into sub-regions based on nuclei position. Thus the Voronoi diagram lines and their colour indicate the spatial relationship of nuclei to each other, for example, larger tessellation and brighter colours show that a larger region is taken up by a nucleus. This showed EC distribution to be altered, particularly in the basilar artery (BA) or midbrain vessels.

This suggested that the effect of lack of blood flow becomes more severe over time and that central vessels are more impacted than peripheral vessels.

Vascular patterning in the trunk is preserved, but vascular morphology altered

We next examined vascular patterning in the trunk of the same animals to study whether the observed effects were conserved or different in these vascular beds (Fig. 3A, B, C, D, E, F, G, H, I, J, K and L). Vessels formed by vasculogenesis were observed and in contrast to the cerebral vessels, trunk vessel patterning was largely unaltered in the absence of flow. However, the morphology of the caudal vein plexus (CVP) was less defined upon lack of blood flow (Fig. 3, white arrowhead) and intussusceptive pillars were lacking (Fig. $3 \mathrm{~A}^{\prime}, \mathrm{E}^{\prime}$ and $\mathrm{I}^{\prime}$ ). All our observations were consistent with previous studies that blood flow is required for plexus to caudal vein remodelling (56). Intussusception, and dorsal aorta (DA)-to-CVP segregation (57), but not intersegmental vessel (ISV) migration (17).

We next examined whether trunk EC numbers were changed. Examination of EC nuclei suggested EC numbers in the trunk were less severely impacted by lack of blood flow in comparison to cerebral vessels (Fig. 4), with EC

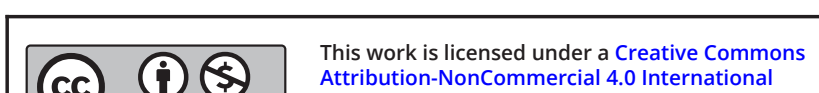
Attribution-NonCommercial 4.0 International License. 
A

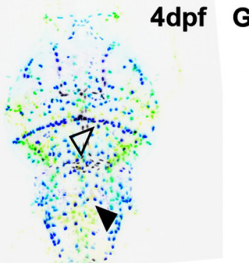

D

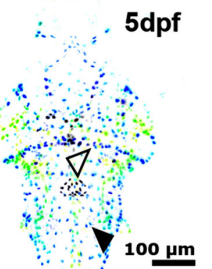

M 10

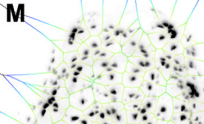

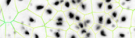

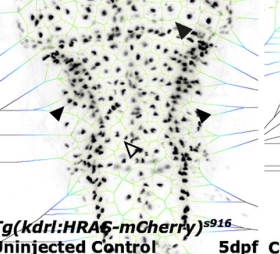

Uninjected Contrò

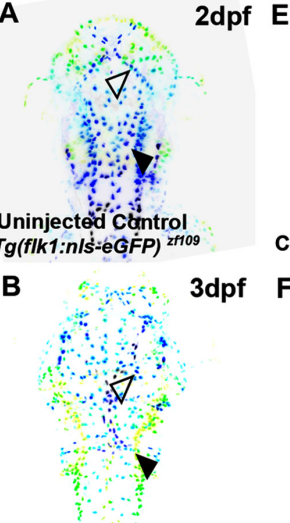

dpf $E$
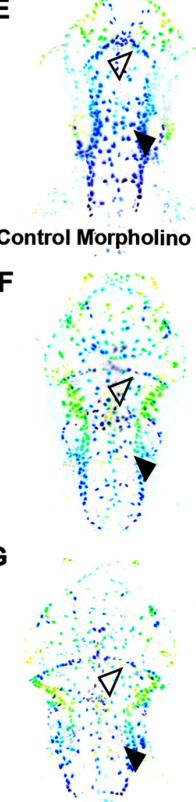

H

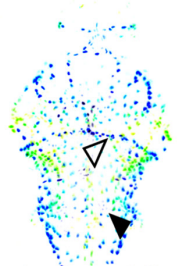

N
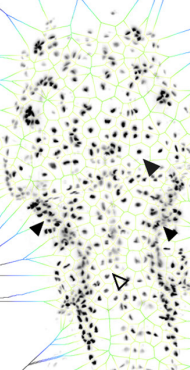

I

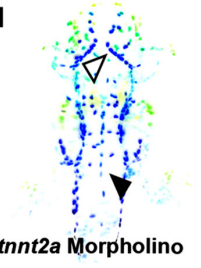

J

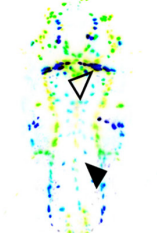

K

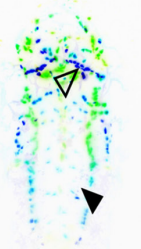

$\mathbf{L}$

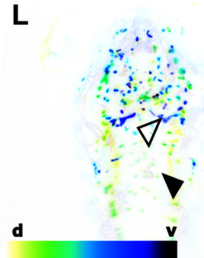

o

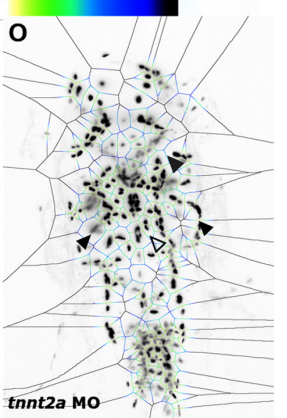

Figure 2

Lack of blood flow impacts cerebral EC number. (A, B, C and D) Cerebral EC nuclei from 2 to $5 \mathrm{dpf}$ in Tg(flk1:n/s-eGFP)zf109 uninjected control. (E, F, G and $\mathrm{H})$ Cerebral EC nuclei in control MO. ( $\mathrm{I}, \mathrm{J}, \mathrm{K}$ and $\mathrm{L})$ Cerebral EC nuclei in tnnt2a MO ( $n=7-10$; two experimental repeats). Comparison of cerebral EC nuclei shows reduced cell numbers in tnnt2a $\mathrm{MO}$ with CtAs (filled arrowhead) being particularly affected ( $\mathrm{d}$ - dorsal, $\mathrm{v}$ - ventral; representative images colour-coded by depth). ( $\mathrm{M}, \mathrm{N}$ and $\mathrm{O}$ ) Voronoi (image partitioning based on nuclei position) diagrams of cerebral EC nuclei suggests nuclei numbers to be maintained in peripheral vessels such as the PHBC (white arrowheads), while EC density is reduced in the midbrain (grey arrowhead) and BA (unfilled arrowhead).

distribution in animals without blood flow being similar in the CV but altered in ISVs (Fig. 4M, $\mathrm{N}$ and $\mathrm{O}$ ).

Together, this suggested that vascular growth patterns in the trunk were unaltered, but remodelling, including intussusception, were lacking and that this is accompanied by changes in EC numbers and distribution.

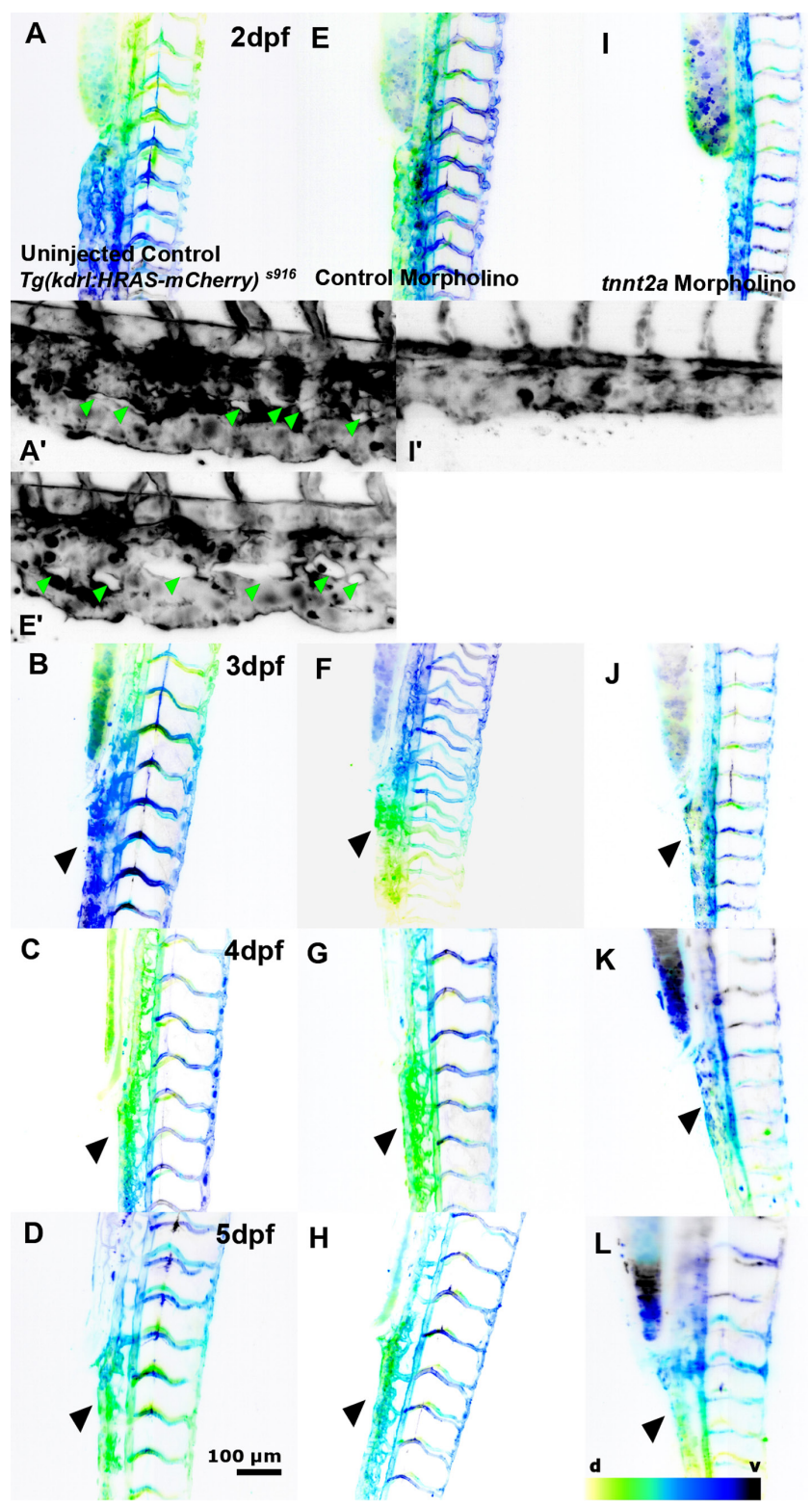

Figure 3

The effect of absent blood flow on trunk vessel development. (A, B, C and D) Trunk vasculature from 2 to $5 \mathrm{dpf}$ in $T g(k d r l: H R A S-m C h e r r y)$ s916 uninjected control. $(\mathrm{E}, \mathrm{F}, \mathrm{G}$ and $\mathrm{H})$ Trunk vasculature in control $\mathrm{MO}(n=7-10$; two experimental repeats). ( $\mathrm{I}, \mathrm{J}, \mathrm{K}$ and $\mathrm{L}$ ) Trunk vasculature in tnnt2a $\mathrm{MO}$. Topology of the trunk vasculature is established in the absence of flow, but morphology of the CV is severely altered (black arrowheads) and intussusceptions are lacking (green arrowhead; $d$ - dorsal, $v$ - ventral; representative images colour-coded by depth).

\section{Lack of blood flow affects vascular area and EC number}

To elucidate the effect of absent blood flow over time, we quantified cerebrovascular area (vascular voxels in 2D (MIPs)). This was significantly reduced in tnnt2a morphants from 2 to $5 \mathrm{dpf}$ (Fig. $5 \mathrm{~A}$; uninjected control 
A

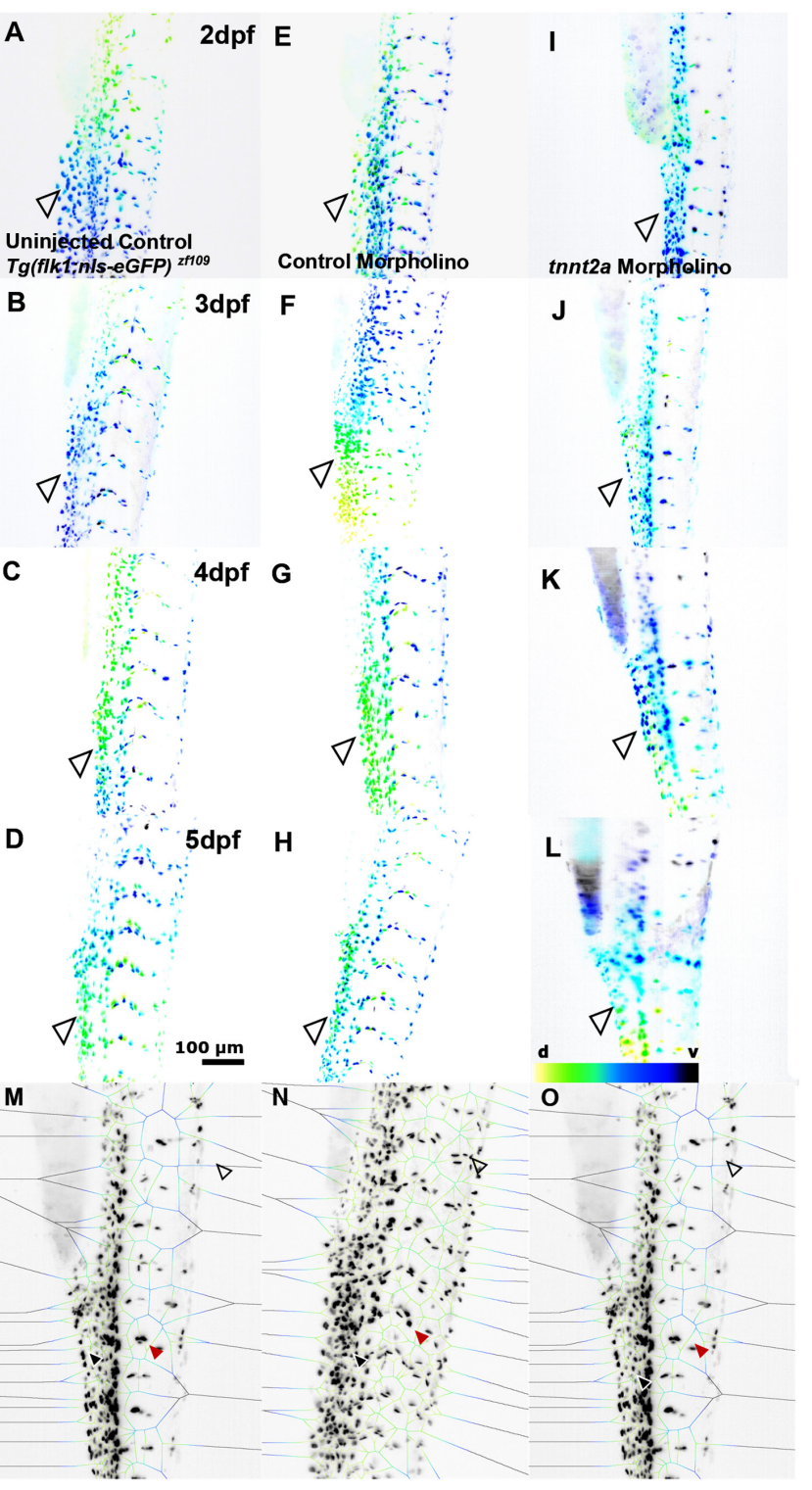

Figure 4

Lack of blood flow impacts trunk EC number. (A, B, C and D) Trunk EC nuclei from 2 to $5 \mathrm{dpf}$ in $\mathrm{Tg}(\mathrm{flk} 1$ :n/s-eGFP)zf109 uninjected control. (E, F, G and $\mathrm{H})$ Trunk EC nuclei in control MO. (I, J, K and L) Trunk EC nuclei in tnnt2a $\mathrm{MO}$ ( $n=7-10$; two experimental repeats). Visual comparison of trunk EC nuclei suggests comparable numbers between treatment groups ( $d$ - dorsal, v - ventral; representative images colour-coded by depth). ( $\mathrm{M}, \mathrm{N}$ and $\mathrm{O}$ ) Voronoi analysis of trunk EC nuclei shows EC distribution is maintained in the CV (black arrowhead), a decrease is observed in ISVs (red arrowhead), and significant changes are observed more anteriorly (unfilled arrowhead).

2dpf $P<0.0001$, 3dpf $P<0.0001$, 4dpf $P<0.0001$, 5dpf $P<0.0001)$, with similar results in craniovascular branch points (Supplementary Fig. 3A). Similarly, the number of cerebral EC nuclei was significantly reduced in tnnt $2 a$ morphants from 2 to 5dpf; while EC number almost doubled from 2 to $5 \mathrm{dpf}$ in controls, EC numbers were almost unaltered in fish without blood flow (Fig. 5B; uninjected control $2 \mathrm{dpf} P=0.0409$, 3dpf $P<0.0001,4 \mathrm{dpf}$ $P<0.0001,5 \mathrm{dpf} P<0.0001)$. To examine the relationship between vascular area and EC nuclei number, vascular area-to-nuclei ratios were calculated (Fig. 5E), showing a decrease in uninjected controls (0.78-fold-change 2-5dpf) and control MO (0.87-fold-change $2-5 \mathrm{dpf})$, while the ratio increased in tnnt $2 a$ MO (1.69-fold-change 2-5dpf). This showed that the number of nuclei-to-vasculature increased in controls but decreased in animals without blood flow.

We performed the same analysis on the trunk, and found that vascular area was significantly reduced by absent blood flow at $2 \operatorname{dpf}(P=0.0074)$ and $3 \operatorname{dpf}(P=0.0195)$, but not $4 \mathrm{dpf}(P=0.1904)$ and $5 \mathrm{dpf}(P>0.9999)$ in tnnt $2 a$ MO (Fig. 5C). Additionally, the number of nuclei was not significantly lower at $2 \mathrm{dpf}(P=0.1514$; Fig. 5D) but was significantly decreased at 3-5dpf (3dpf $P=0.0018$, 4dpf $P=0.0013$, 5dpf $P<0.0001)$. Similar results were observed when assessing trunk vascular branch points as co-metric (Supplementary Fig. 3B). Analysis of vascular-to-nuclei ratio showed that vascular area increased in all three groups (Fig. 5F; fold-change 2-5dpf: uninjected control 1.10, control MO 1.55, tnnt2a MO 2.51). Together, this suggested that cerebral vessels were more severely affected than trunk vessels by the absence of blood flow and that lack of blood flow increases the vascular-to-nuclei ratio in both the brain and trunk.

We next quantified the nuclei nearest neighbour distance (NND), finding it to be decreased in tnnt $2 a \mathrm{MO}$ in both vascular beds (Fig. 5G and $\mathrm{H}$ ), supporting the visual assessment of Voronoi diagrams and previous studies that suggest the less net distance between ECs in the absence of flow (56).

To assess how the observed reduced head size (Supplementary Fig. 4A) related to vascular and nuclei density, vasculature-to-ROI and nuclei-to-ROI ratios were quantified. This showed that for all three groups, vascular coverage was maintained at about 30\% from 2 to $5 \mathrm{dpf}$ (Supplementary Fig. 4B), with ratios higher in tnnt $2 a \mathrm{MO}$ at $5 \mathrm{dpf}$ in comparison to uninjected controls $(P=0.0074)$. Similarly, the nuclei-to-ROI ratios were maintained over time in all three groups (Supplementary Fig. 4C), but with higher ratios in tnnt $2 a \mathrm{MO}$ than in controls.

Together, this showed that even though tnnt2a MO have a reduced head size, vasculature-to-ROI and nuclei-toROI ratios are maintained or even larger than in controls. https://vb.bioscientifica.com

https://doi.org/10.1530/VB-21-0009 (c) 2020 The authors Published by Bioscientifica Ltd

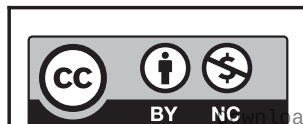

This work is licensed under a Creative Commons Attribution-NonCommercial 4.0 International License. ded from Bioscientifica.com at 04/26/2023 09:56:46AM 
A

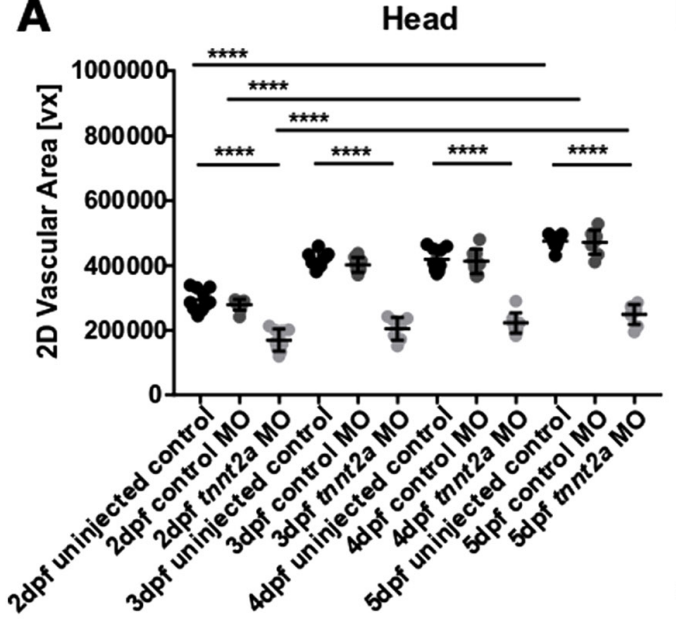

C

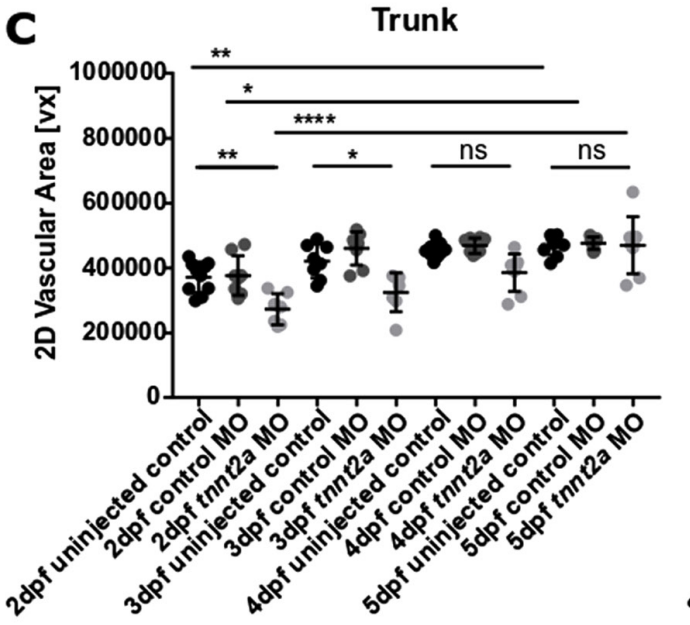

E

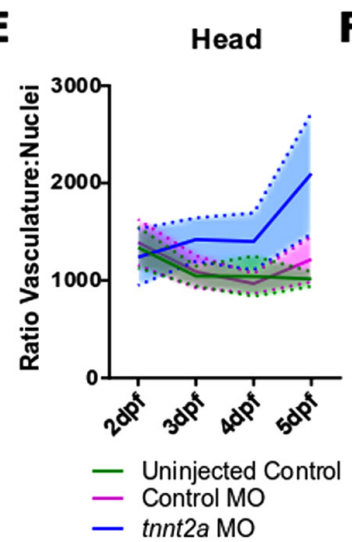

$\mathbf{F}$
B

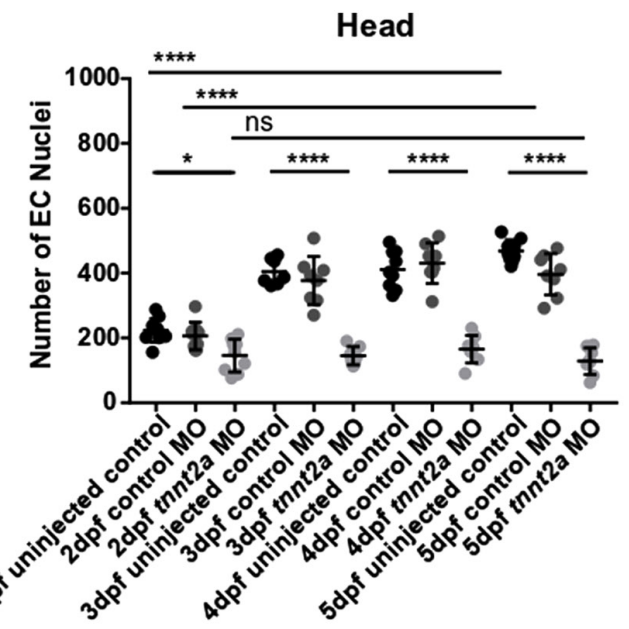

D
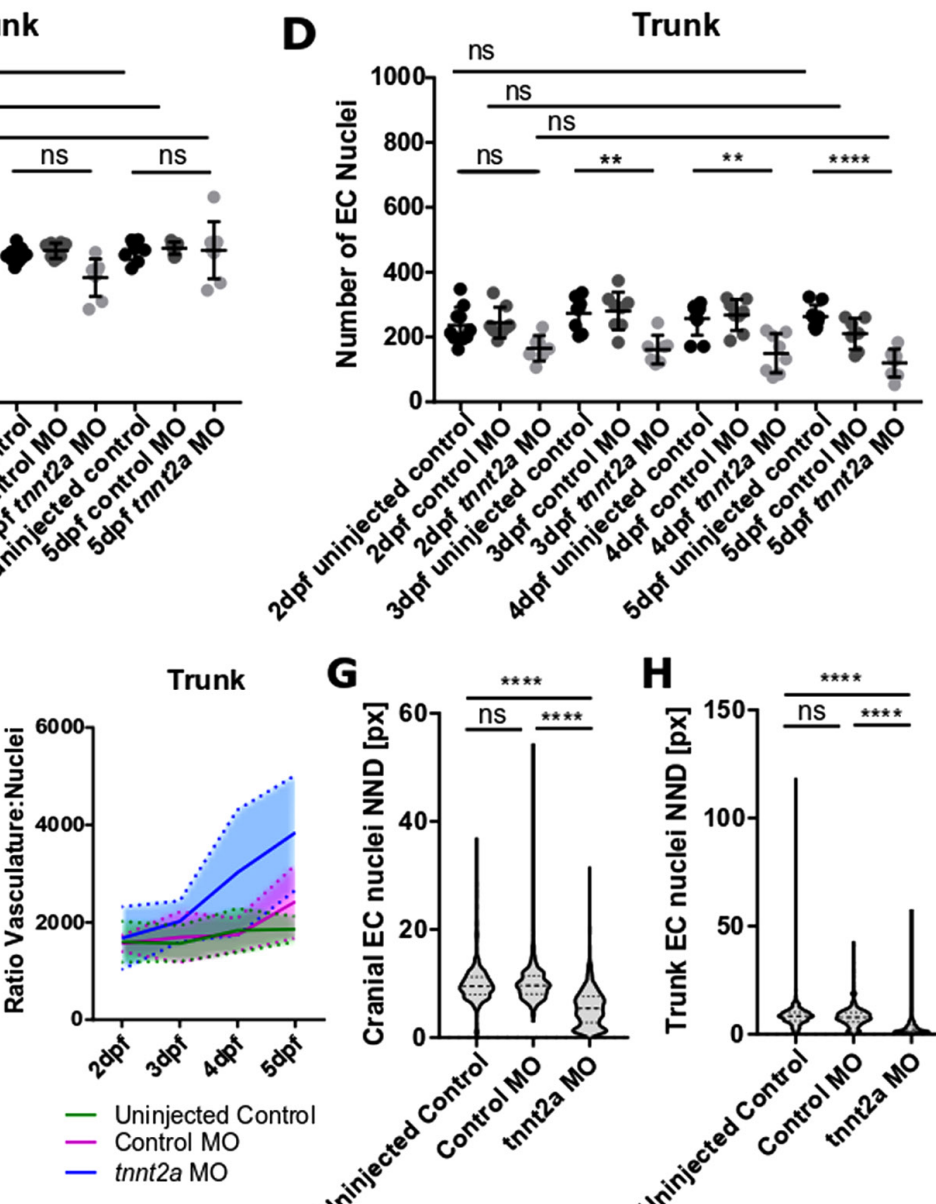
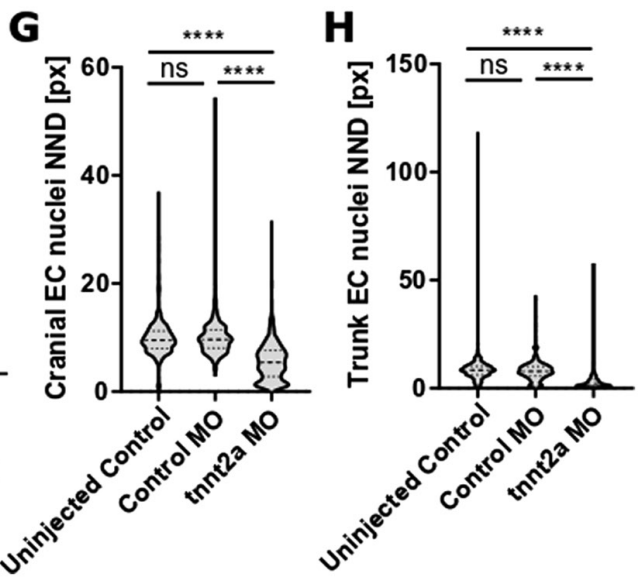

Figure 5

Quantification of vasculature and nuclei. (A) The cerebral vasculature is reduced in tnnt2a MO from 2 to $5 \mathrm{dpf}$ ( $n=7-10$; two experimental repeats).

(B) The number of cerebral EC nuclei is reduced in tnnt2a MO from 2 to $5 \mathrm{dpf}$. (C) The trunk vasculature is reduced in tnnt2a MO at 2-3dpf, but not 4-5dpf ( $n=7$ - 10; two experimental repeats). (D) The number of trunk EC nuclei is not altered in tnnt2a MO at $2 \mathrm{dpf}$, but significantly reduced from 3 to $5 \mathrm{dpf}$. (E) The ratio of cerebral vasculature-to-nuclei remains consistent in uninjected controls (green) and control $\mathrm{MO}$ (magenta), but increases over time in tnnt2a $\mathrm{MO}$ (blue). (F) The ratio of trunk vasculature-to-nuclei remains consistent in uninjected controls (green) and control MO (magenta), but increases over time in tnnt2a MO (blue). (G) Quantification of cerebral nuclei nearest neighbour distance (NND) showed nuclei distance to be decreased in tnnt2a MO in comparison to uninjected controls $(P<0.0001)$ and control $\mathrm{MO}(P<0.0001$; Kruskal-Wallis test). (H) Quantification of trunk nuclei NND showed nuclei distance to be decreased in tnnt2a MO in comparison to uninjected controls $(P<0.0001)$ and control $\mathrm{MO}(P<0.0001$; Kruskal-Wallis test). 
Arterial and venous responses to lack of blood flow are vascular bed dependent

To study whether vessels of different identities were differentially or similarly impacted by lack of blood, we quantified the diameter of selected arteries and veins in the brain and trunk3dpf.Quantification of cerebralBAdiameter showed no difference between tnnt $2 a \mathrm{MO}$ and controls (Supplementary Fig. 5A; uninjected control $P>0.9999$, control MO $P>0.9999)$, while the diameter of the posterior cerebral vein $(\mathrm{PCeV})$ was reduced in animals without blood flow (Supplementary Fig. 5B; uninjected control $P=0.0175$, control MO $P=0.1230)$. BA diameter was reduced by $2.5 \%$ (uninjected control $16.41 \mu \mathrm{m}$; tnnt $2 a \mathrm{MO} 16.00 \mu \mathrm{m}$ ), while the PCeV diameter was reduced by $36.46 \%$ (uninjected control $11.52 \mu \mathrm{m}$; tnnt $2 a$ MO $7.32 \mu \mathrm{m})$. Quantifying trunk ISV diameters, aISV diameter (Supplementary Fig. 5C; uninjected control $P=0.0017$, control MO $P=0.0121$ ) and vISV diameter (Supplementary Fig. 5D; uninjected control $P=0.0010$, control MO $P=0.0094$ ) were both reduced in tnnt $2 a$ MO. The mean diameter of aISVs was reduced by $40.4 \%$ (uninjected control $10.52 \mu \mathrm{m}$; tnnt $2 a \mathrm{MO}$ $6.27 \mu \mathrm{m})$, while the mean diameter of vISVs was reduced

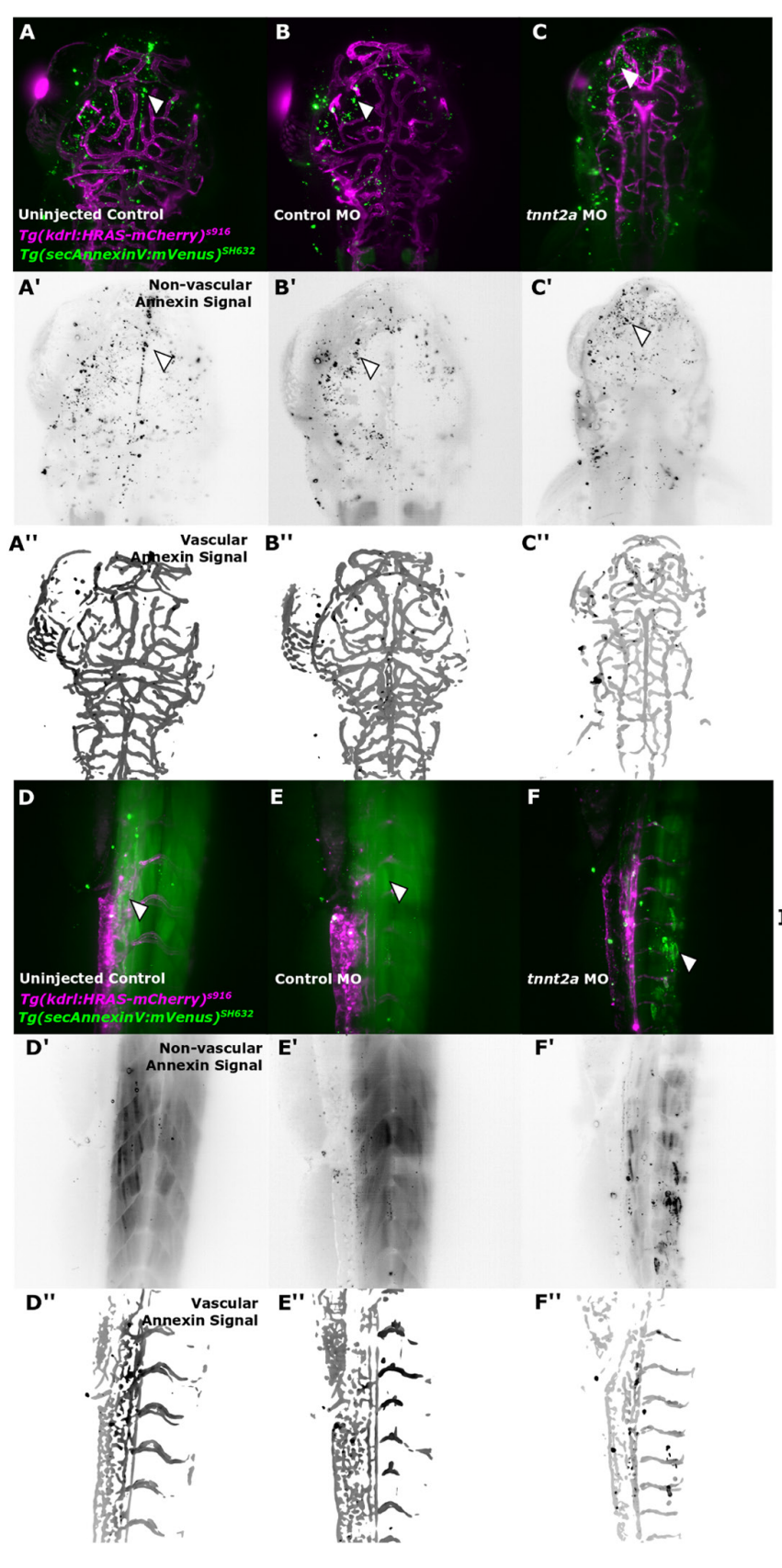

https://vb.bioscientifica.com https://doi.org/10.1530/VB-21-0009
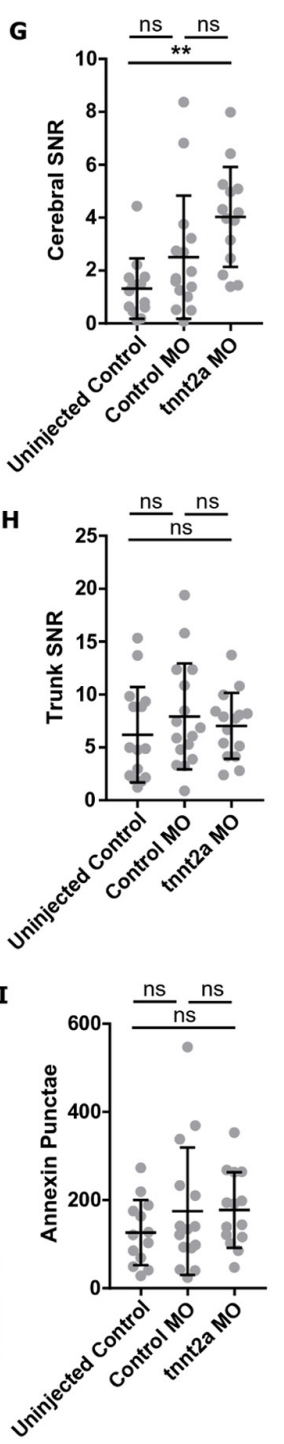

Figure 6

Cell death is increased by absent blood flow. (A, B and $C$ ) Cell death, visualized in the transgenic reporter line $\operatorname{Tg}\left(\right.$ secAnnexinV:mVenus) ${ }^{5 H 632}$ ( $n=$ 13-15; three experimental repeats; 3dpf). (D, E and F) Annexin levels in the trunk vasculature appeared visually similar between groups. (G) Quantification of cerebral annexin SNR showed an increase in tnnt2a $\mathrm{MO}$ in comparison to uninjected controls $(P=0.0012)$ but not control MO ( $P=0.072$; Kruskal-Wallis test). (H) Quantification of trunk annexin SNR showed no increase in tnnt2a $\mathrm{MO}$ in comparison to uninjected controls $(P>0.9999)$ or control MO $(P>$ 0.9999; Kruskal-Wallis test). (I) Quantification of cerebral annexin foci (white arrowheads) showed no increase in tnnt2a $\mathrm{MO}$ in comparison to uninjected controls $(P>0.9999)$ and control MO ( $P=0.4542$; Kruskal-Wallis test). 
by $46.64 \%$ (uninjected control $11 \mu \mathrm{m}$; tnnt $2 a$ MO $5.87 \mu \mathrm{m}$ ). The diameter of the DA (Supplementary Fig. 5E; uninjected control $P=0.0008$, control MO $P=0.0105$ ) as well as the posterior cardinal vein (PCV) (Supplementary Fig. 5F; uninjected control $P=0.0159$, control MO $P=0.0548$ ) were reduced in tnnt $2 a \mathrm{MO}$. The mean diameter of the DA was reduced by $40.76 \%$ (uninjected control $25.86 \mu \mathrm{m}$; tnnt $2 a$ MO $15.32 \mu \mathrm{m})$, while the mean diameter of the PCV was reduced by $29.1 \%$ (uninjected control $27.46 \mu \mathrm{m}$; tnnt $2 a \mathrm{MO}$ $19.47 \mu \mathrm{m})$. This suggested that vessel diameter is impacted by flow in the vessel of venous and arterial identity in the trunk, while arterial vessel calibre of the BA is unaltered without flow.

To further examine whether EC number was affected by vessel identity and/or vascular bed, EC nuclei per vessel were quantified. Analysis of nuclei of cerebral BA and PCeV in $80 \mu \mathrm{m}$ ROI showed no significant difference between those vessels in the examined treatment groups and no significant change upon lack of blood flow (Supplementary Fig. 5G). Quantification of nuclei in trunk aISV and vISV showed no significant difference in EC numbers between vessels of different identity (Supplementary Fig. 5H). Upon lack of blood flow arterial EC number was not reduced $(P=0.5756)$, but venous EC number was significantly reduced $(P=0.0005)$.

Together, this suggests that vascular responses are vascular-bed as well as vascular-identity specific.

\section{Non-EC-specific cell death is increased by absent blood flow}

To examine whether cell death contributed to the reduced EC numbers observed in tnnt $2 a$ morphants, we quantified this using the transgenic $T g(\sec A n n e x i n V: m V e n u s)^{S H 632}$ and the live dye Acridine Orange.

Visual inspection of the transgenic reporter line suggested an overall increase in cell death in tnnt $2 a \mathrm{MO}$ compared to controls in the head (Fig. 6A, B and C) but not trunk (Fig. 6D, E and F), with specific foci found in the brain (white arrowhead). To examine whether the observed increase in annexin levels was vascular or non-vascular, we extracted non-vascular (Fig. 6A', B', $\mathrm{C}^{\prime}, \mathrm{D}^{\prime}, \mathrm{E}^{\prime}$ and $\mathrm{F}^{\prime}$ ) from vascular (Fig. 6A", B", C", D", E" and F") signal by producing vascular masks in $3 \mathrm{D}$, finding that the observed cell death was not EC-specific. Quantification of tissue signal-tonoise ratio (SNR; Fig. 6G and $\mathrm{H}$ ) showed an increase in the head in tnnt $2 a \mathrm{MO}$ compared with uninjected controls $(P=0.0012$, Fig. 6G) but not trunk $(P>0.9999$, Fig. $6 \mathrm{H})$. The number of annexin foci was not increased in tnnt $2 a$ MO (Fig. 6I; uninjected control $P>0.9999$ ).
To examine this further, the same experiments were conducted using the live dye Acridine orange, which showed similar results. However, cell death foci were clearly increased in fish without blood flow using the Acridine Orange assay (Supplementary Fig. 6).

Together, this suggests that overall cell death is increased in tnnt $2 a \mathrm{MO}$, not restricted to EC.

\section{Inflammatory responses are not triggered by the absence of blood flow}

We next examined whether immune cell numbers would be altered due to the observed cell death potentially triggering an inflammatory response, or local tissue ischemia due to lack of blood flow, equally triggering an inflammatory response (58). As the observed effects of lack of blood flow were more severe in the head vasculature, quantification was only performed in this vascular bed.

Quantification of the number of macrophages in controls and tnnt $2 a \mathrm{MO}$ at $3 \mathrm{dpf}$ (Fig. 7A, B and C) showed no difference between groups (Fig. 7D; $P=0.2356$ ). Similarly, no difference was found in intracranial neutrophil numbers at $3 \mathrm{dpf}$ when comparing tnnt $2 a \mathrm{MO}$ to controls (Fig. 7E, F and $\mathrm{G} ; P=0.1708)$.

To further examine whether the observed cell death was associated with altered tissue inflammation in the absence of altered macrophage and neutrophil numbers, we visualised the inflammatory mediator nitric oxide (NO) using the live dye DAF-FM. The visual assessment showed no difference in DAF-FM levels in the head (Fig. 8A, B and $\mathrm{C}$ ) and trunk (Fig. D, E and F). This was confirmed by SNR quantification in the head (Fig. 8G; $P=0.7967$ ) and trunk (Fig. 8H; $P=0.9371$ ) which showed no differences comparing samples with blood flow to samples without blood flow.

Interestingly, we observed that the DAF-FM signal, previously described to be localized in the bulbus arteriosus after 2 dpf (59), was absent in fish without blood flow (Supplementary Fig. 7), suggesting bulbus arteriosus NO expression is blood flow-dependent.

Together, our data suggested that the lack of blood flow does increase cell death but not tissue inflammation or immune cell recruitment at the investigated time-point.

Sprouting angiogenesis is altered but not halted by lack of blood flow

We next examined whether the observed changes in vascular patterning were due to changes in angiogenic

This work is licensed under a Creative Commons Attribution-NonCommercial 4.0 International License. 

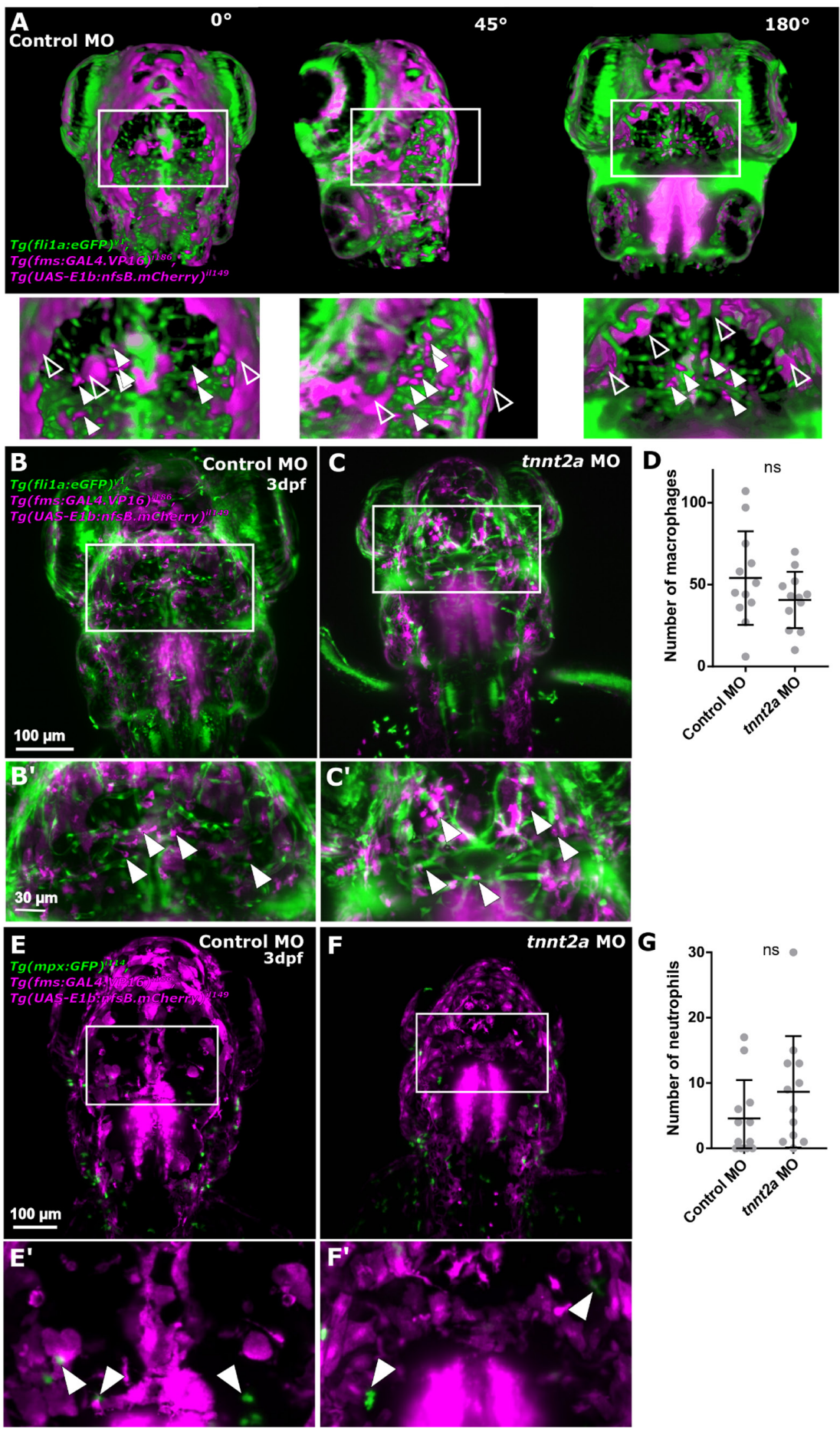

Figure 7

Lack of blood flow does not impact the number of cerebral innate immune cells. (A) Identification of immune cells was performed in 3D, allowing to discern non-specific signal (unfilled arrowhead) from immune cells (filled arrowhead). (B and C) Macrophages (magenta) were quantified examining the transgenic Tg(fli1a:eGFP)y1, Tg(fms:GAL4.VP16)i186, Tg(UAS-E1b:nfsb.mCherry)ili49. (D) Number of macrophages was not changed upon blood flow loss $\left(P=0.2356 ; n=12 ; 3 \mathrm{dpf}\right.$; Mann-Whitney $U$ test). (E and F) Neutrophils (green) were examined in the transgenic reporter line $\operatorname{Tg}(\mathrm{mpx}: G F P)^{i 114}, \mathrm{Tg}(f m s: G A L 4$. VP16)i186, $\operatorname{Tg}($ UAS-E1 b:nfsb.mCherry)ili49. (G) Number of neutrophils was not changed upon blood flow loss $(P=0.1708 ; n=12 ;$ two experimental repeats; 3dpf; Mann-Whitney $U$ test). 


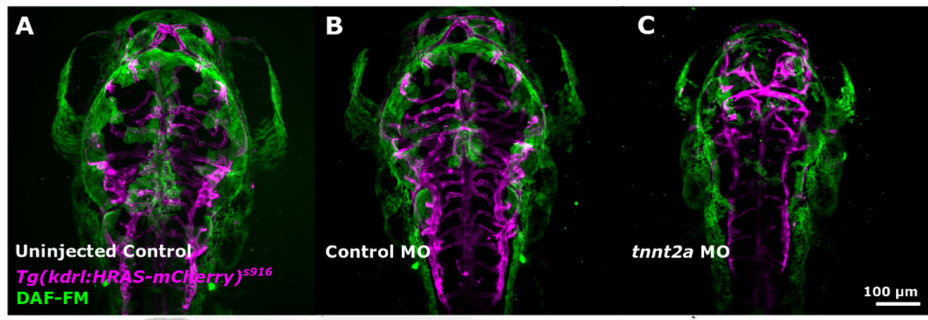

A'

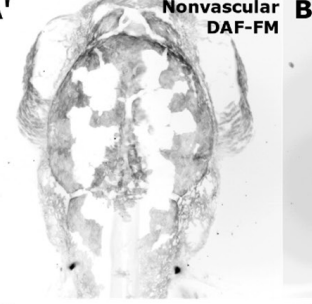

A"

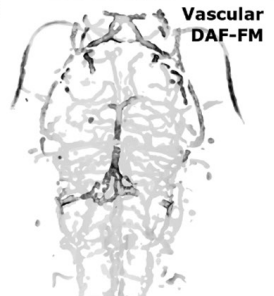

$\mathbf{C}^{\prime}$

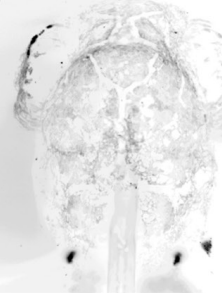

\section{"}
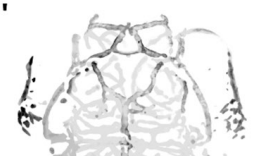

C'
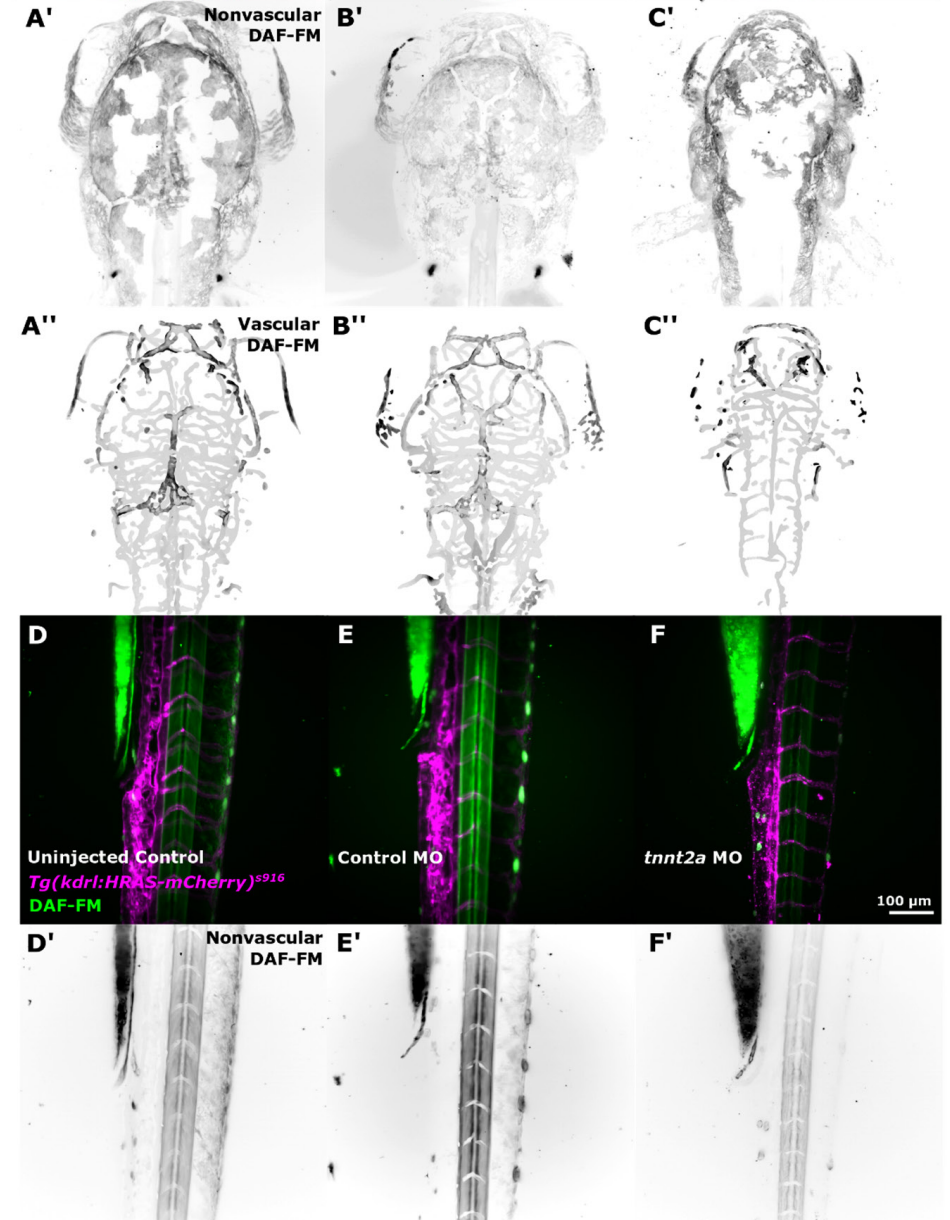

D"

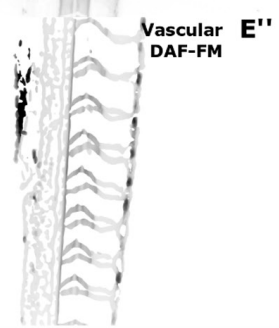

.

$F^{\prime}$

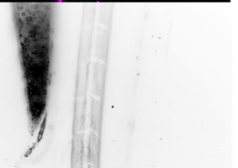

F"
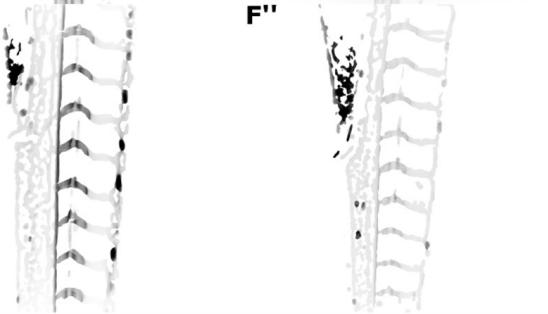
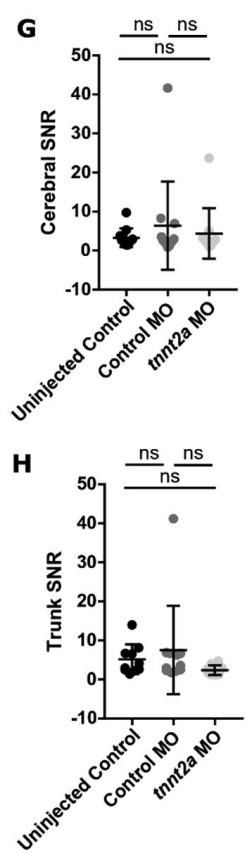

Figure 8

Inflammation is not increased by absent blood flow. (A, B and C) Examining nitric oxide (NO; visualized by DAF-FM) as an inflammatory marker, showed similar levels of $\mathrm{NO}$ in the head of uninjected controls, control MO, and tnnt2a $\mathrm{MO}$ (uninjected control $n=11$, control $\mathrm{MO} n=12$, tnnt2a $\mathrm{MO} n=11$; three experimental repeats; 3dpf). (D, E and F) DAF-FM levels in the trunk vasculature appeared visually similar between groups. (G) Quantification of cerebral DAF-FM SNR showed no difference between tnnt2a MO and uninjected controls ( $P>0.9999)$ or control MO $(P>0.9999 ;$ Kruskal-Wallis test). (H) Quantification of trunk DAF-FM SNR showed no difference between tnnt2a MO and uninjected controls $(P=0.1391)$ or control MO $(P=0.1216$; KruskalWallis test). 
sprouting. To examine this, we first examined trunk ISV sprouting and subsequent dorsal longitudinal anastomotic vessel (DLAV) formation, which are known to develop in a highly stereotypic anterior-to-posterior growth pattern. Comparison of time-lapse data in controls and embryos without blood flow (Supplementary Fig. 8A), showed that ISVs are competent to sprout in fish with blood flow, as previously suggested (17). Also in agreement with previous studies, we did not observe inverse membrane blebbing to occur in the absence of flow (60). However,DLAV anastomosis is delayed in fish without flow. Following the initial delay, ISVs sprout laterally to form the DLAV upon anastomosis. While vessels in controls become subsequently perfused upon anastomosis, this is not the case in fish without blood flow.

We next examined cerebrovascular sprouting by examining CtA sprouting and numbers, due to their stereotypic sprouting pattern from the PHBC and anastomosis with the BA. This showed that CtA's were able to sprout from the PHBC and merge with the BA (Supplementary Fig. 8B) and when quantifying the number of sprouts this showed no significant difference in sprout number in fish without blood flow (Supplementary Fig. 8C; uninjected controls $P=0.4737$ ). However, quantification of CtA's merged to the BA, were significantly reduced in the absence of blood flow (Supplementary Fig. 8D; uninjected controls $P=0.0005$ ).

Importantly, for all examined vessels stereotypic patterning was observed in the absence of flow, suggesting that path-finding is dependent on factors other than blood flow.

\section{Discussion}

In this study, we present the first assessment of the impact of blood flow on zebrafish embryonic vascular development from 2 to $5 \mathrm{dpf}$, and present the first comparison of the impact of flow in two vascular beds, namely the head and trunk. We show that though the overall response to lack of blood flow is similar in both vascular beds, the head vasculature is more severely impacted than trunk vasculature, with intra-cerebral vessels particularly being affected. Additionally, the effect of absent blood flow increases over time. Our data show that lack of blood flow significantly increases cell death without significant cell death in ECs, without evidence of a significant increase of tissue inflammation, as quantified by cerebral immune cell numbers and nitric oxide (Table 1).
Our work complements previous work (33), which found blood flow cessation to induce EC apoptosis in zebrafish embryos at $30 \mathrm{hpf}$, while our assessment of cerebral macrophage numbers extends the examinations of Xu et al. who limited their studies to macrophage of the tectum (61). Our finding that NO is lacking in the bulbus arteriosus at $3 \mathrm{dpf}$ in fish without blood flow is the first functional evidence of bulbus arteriosus NO to be blood flow-dependent (59).

Our data showed that even in the complete absence of flow, stereotypic vascular patterning is preserved in the trunk and peripheral cerebral vessels. Our findings show that sprouting angiogenesis occurs in both vascular beds in the absence of flow but that anastomosis is delayed in the trunk and reduced in the head. This shows that in both, the trunk and head vasculature, vascular sprouting and path-seeking can occur in the absence of flow and is therefore not solely dependent on pressure gradients but likely to be induced by molecular or biochemical cues. However, successful fusion and anastomosis are blood flow dependent in both examined vascular beds. In agreement with previous work, we find that vascular plexus remodelling $(56,57)$ and vascular lumenization are blood flow-dependent (60). While previous studies suggest that pruning is directly driven by blood flow (19), it was never shown that this is the case for vessels that have never experienced blood flow. Our data show that early vascular networks are established. We suggest that, particularly in the head, multiple mechanisms contribute to the altered vascularization (a) lacking vascular selffusion and remodelling in the absence of flow could be

Table 1 Overview of vascular properties altered upon lack of blood flow.

\begin{tabular}{|c|c|c|}
\hline & \multicolumn{2}{|c|}{ Without blood flow } \\
\hline & Head & Trunk \\
\hline Vasculogenesis & Yes & Yes \\
\hline Angiogenic sprouts & Yes & Yes \\
\hline Anastomosis & Reduced & Delayed \\
\hline Inverse membrane blebbing & $\mathrm{N} / \mathrm{A}$ & No \\
\hline Kugeln & No & N/A \\
\hline Cell death & Increased & No \\
\hline Macrophages and neutrophils & No & N/A \\
\hline DAF-FM & No & No \\
\hline Vascular area & Reduced & Reduced \\
\hline EC number & Reduced & Reduced \\
\hline Vasculature:nuclei ratio & Increased & Increased \\
\hline NND & Reduced & Reduced \\
\hline $\mathrm{BP}$ & Reduced & Reduced \\
\hline Artery diameter & No & Reduced \\
\hline Vein diameter & Reduced & Reduced \\
\hline Artery nuclei & No & No \\
\hline Vein nuclei & No & Reduced \\
\hline
\end{tabular}

is work is licensed under a Creative Common Attribution-NonCommercial 4.0 International License. ded from Bioscientifica.com at 04/26/2023 09:56:46AM 
the mechanism for the observed phenotype, as suggested for the subintestinal vein (23); (b) reduced vascular stabilization $(62,63)$; (c) potentially changed EC polarity and maintenance needs to be examined (18).

Critically, our work shows that vessel identity affects cell response to flow and that this is furthermore impacted by the vascular bed. Thus, we suggest that even though genetic factors establish vascular identity prior to blood flow $(64,65)$, the fine-tuning of vascular response is likely to be caused by extrinsic vascular-bed-specific signaling molecules or biochemical cues (7).

Our data show that EC nuclei net distance is reduced in the absence of flow by examination of NND and Voronoi tessellation. Our study suggests that this might be in part due to a reduced vascular area (i.e. vasculature and nuclei numbers are reduced; vascularto-nuclei ratios are unaltered in early development but changed with age) rather than significantly altered cell movements as nuclei are observed in all formed vessels. However, it has been previously shown that ECs migrate against the flow, thus the lack of blood flow might also alter EC net distance via migration changes (66).

Our studies show that cerebral EC cell numbers double from 2 to $5 \mathrm{dpf}$ in controls but remain stationary in fish without blood flow. Even though we observe cell death, there is a high likelihood that decreased proliferation due to the lack of blood flow is a contributing factor (67).

Once established blood vessels are established, also their EC properties and functions rely on blood flow, as it was previously shown regarding maintenance $(7,62,63$, $68)$, polarity $(66,69)$, and kugeln (9).

The finding that central cerebral vessels show severely altered growth patterns, while peripheral vessels are less impacted, suggests that the response to blood flow is different in different vascular territories; whether this is due to a difference in vessel formation (e.g. peripheral vessels are formed from angiogenesis-derived clusters, while central vessels are formed by angiogenesis from primary vessels) $(70,71)$ or identity (e.g. perineural, extra-cerebral, vs intra-cerebral) (72) requires future investigation.

The mechanisms of the observed effects in response to absent blood flow still require future investigation. This could include examining the expression of different mechanoreceptors and EC properties to complement previous findings about the importance and impact of blood flow $(32,73,74,75,76,77)$. Similarly, molecular pathways and their context-dependent interpretation (such as VEGF, BMPs, Wnt $(62,78,79,80)$ ) might play a role in encountered differences in the head and trunk vasculature.

Together, our findings emphasize the important role of blood flow in vascular patterning and development and highlight different responses in different vascular territories to mechanical stimuli.

\section{Key points}

- We here use zebrafish as a model to quantitatively assess the impact of the lack of blood flow in development and compare its impact in two vascular beds, namely the cerebral to trunk vasculature.

- In both vascular beds, vascular growth and endothelial cell number are reduced by lack of blood flow, with increasing effect size from 2-5 days post fertilization.

- Examination of vascular patterning shows that while in the absence of flow vasculogenesis and sprouting occur, anastomosis is delayed in the trunk and reduced in the head.

- Studying differential responses in vessel types, we found that vascular responses to absent blood flow are vascular-bed as well as vascular-identity specific.

- We found non-EC-specific cell death to be increased in both vascular beds, with a larger effect size in the brain, but that this cell death occurs without triggering recruitment of immune cells (macrophages or neutrophils) or tissue inflammation.

\section{Supplementary materials}

This is linked to the online version of the paper at https://doi.org/10.1530/ VAB-21-0009.

\section{Declaration of interest}

Timothy Chico is an Editorial Board Member of Vascular Biology. Timothy Chico was not involved in the review or editorial process for this paper, on which he is listed as an author. The other authors declare that they have no conflict of interest.

\section{Funding}

This work was supported by a University of Sheffield, Department of Infection, Immunity and Cardiovascular Disease, Imaging and Modelling Node Studentship and an Insigneo Institute for in silico Medicine Bridging fund awarded to E K. R S was funded by the Medical Research Council Discovery Medicine North Doctoral Training Partnership. G B was funded by NC3Rs and the British Heart Foundation. J S-C was funded by the British Heart Foundation FS/18/2/33221. N H is funded by Association Européenne contre les Leucodystrophies, Grant/Award Number: ELA 2016-012F4. P C E was funded by NC3Rs and the British Heart Foundation RG/19/10/34506. 
The Zeiss Z1 light-sheet microscope was funded via British Heart Foundation Infrastructure Award IG/15/1/31328 awarded to T C.

\section{Author contribution statement}

Funding obtained by E K, P A, T C, J S-C, N H, and P C E; data acquisition, E K, R S, G B, and K P; investigation, validation, and data curation, E K; formal visualization and analysis, E K; resources, $P$ A, T C, J S-C, N H, and P C E; project administration, $\mathrm{E} \mathrm{K}$ and $\mathrm{P} \mathrm{A}$; writing - original draft, $\mathrm{E} \mathrm{K}$; writing review and editing, all authors. T $C$ and $P$ A: joint senior authors.

\section{Acknowledgements}

The authors are grateful to Heba Ismail for feedback, Deepak Ailani for sharing chemicals, and Fiona Wright for technical support, as well as the Bateson Centre Zebrafish Facility Staff for support and advice. The authors thank all funders, including the University of Sheffield Department of Infection, Immunity and Cardiovascular Disease, Insigneo Institute for in silico Medicine, Medical Research Council, NC3Rs, and the British Heart Foundation. The authors also thank the reviewers for their in-depth invaluable feedback to improve the manuscript.

\section{References}

1 Demir R, Yaba A \& Huppertz B. Vasculogenesis and angiogenesis in the endometrium during menstrual cycle and implantation. Acta Histochemica 2010112 203-214. (https://doi.org/10.1016/j. acthis.2009.04.004)

2 Jung S \& Kleinheinz J. Angiogenesis - the key to regeneration. In Regenerative Medicine and Tissue Engineering, pp. 443-472, 2013. (https://doi.org/10.5772/55542)

3 Singer AJ \& Clark RAF. Cutaneous wound healing. New England Journal of Medicine 1999341 738-746. (https://doi.org/10.1056/ NEJM199909023411006)

4 Feigin VL, Norrving B \& Mensah GA. Global burden of stroke. Circulation Research 2017120 439-448. (https://doi.org/10.1161/ CIRCRESAHA.116.308413)

5 Lackland DT \& Weber MA. Global burden of cardiovascular disease and stroke: hypertension at the core. Canadian Journal of Cardiology 201531 569-571. (https://doi.org/10.1016/j.cjca.2015.01.009)

6 Abbott NJ, Patabendige AAK, Dolman DEM, Yusof SR \& Begley DJ. Structure and function of the blood-brain barrier. Neurobiology of Disease 201037 13-25. (https://doi.org/10.1016/j.nbd.2009.07.030)

7 Chico TJA \& Kugler EC. Cerebrovascular development: mechanisms and experimental approaches. Cellular and Molecular Life Sciences 2021 78 4377-4398. (https://doi.org/10.1007/s00018-021-03790-1)

8 Huntley MA, Bien-Ly N, Daneman R \& Watts RJ. Dissecting gene expression at the blood-brain barrier. Frontiers in Neuroscience $2014 \mathbf{8}$ 355. (https://doi.org/10.3389/fnins.2014.00355)

9 Kugler EC, van Lessen M, Daetwyler S, Chhabria K, Savage AM, Silva V, Plant K, MacDonald RB, Huisken J, Wilkinson RN, et al. Cerebrovascular endothelial cells form transient Notch-dependent cystic structures in zebrafish. EMBO Reports 201920 e47047. (https:// doi.org/10.15252/embr.201847047)

10 Vanlandewijck M, He L, Mäe MA, Andrae J, Ando K, Del Gaudio F, Nahar K, Lebouvier T, Laviña B, Gouveia L, et al. A molecular atlas of cell types and zonation in the brain vasculature. Nature 201855 475-480. (https://doi.org/10.1038/nature25739)

11 Bakkers J. Zebrafish as a model to study cardiac development and human cardiac disease. Cardiovascular Research 201191 279-288. (https://doi.org/10.1093/cvr/cvr098)
12 Chico TJA, Ingham PW \& Crossman DC. Modeling cardiovascular disease in the zebrafish. Trends in Cardiovascular Medicine 200818 150-155. (https://doi.org/10.1016/j.tcm.2008.04.002)

13 Gut P, Reischauer S, Stainier DYR \& Arnaout R. Little fish, big data: zebrafish as a model for cardiovascular and metabolic disease. Physiological Reviews 201797 889-938. (https://doi.org/10.1152/ physrev.00038.2016)

14 Lawson ND \& Weinstein BM. In vivo imaging of embryonic vascular development using transgenic zebrafish. Developmental Biology 2002 248 307-318. (https://doi.org/10.1006/dbio.2002.0711)

15 Huisken J, Swoger J, Del Bene F, Wittbrodt J \& Stelzer EHK. Optical sectioning deep inside live embryos by selective plane illumination microscopy. Science 2004305 1007-1009. (https://doi.org/10.1126/ science.1100035)

16 Isogai S, Horiguchi M \& Weinstein BM. The vascular anatomy of the developing zebrafish: an atlas of embryonic and early larval development. Developmental Biology 2001230 278-301. (https://doi. org/10.1006/dbio.2000.9995)

17 Isogai S, Lawson ND, Torrealday S, Horiguchi M \& Weinstein BM. Angiogenic network formation in the developing vertebrate trunk. Development 2003130 5281-5290. (https://doi.org/10.1242/dev.00733)

18 Campinho P, Vilfan A \& Vermot J. Blood flow forces in shaping the vascular system: a focus on endothelial cell behavior. Frontiers in Physiology 202011 552. (https://doi.org/10.3389/fphys.2020.00552)

19 Chen Q, Jiang L, Li C, Hu D, Bu JW, Cai D \& Du JL. Haemodynamicsdriven developmental pruning of brain vasculature in zebrafish. PLoS Biology 201210 e1001374. (https://doi.org/10.1371/journal. pbio.1001374)

20 Hove JR, Koster RW, Forouhar AS, Acevedo-Bolton G, Fraser SE \& Gharib M. Intracardiac fluid forces are an essential epigenetic factor for embryonic cardiogenesis. Nature 2003421 172-177. (https://doi. org/10.1038/nature01282)

21 Kochhan E, Lenard A, Ellertsdottir E, Herwig L, Affolter M, Belting HG \& Siekmann AF. Blood flow changes coincide with cellular rearrangements during blood vessel pruning in zebrafish embryos. PLoS ONE 20138 e75060. (https://doi.org/10.1371/journal. pone.0075060)

22 Lee J, Fei P, Packard RRS, Kang H, Xu H, Baek KI, Jen N, Chen J, Yen H, Kuo CC, et al. 4-Dimensional light-sheet microscopy to elucidate shear stress modulation of cardiac trabeculation. Journal of Clinical Investigation 2016126 1679-1690. (https://doi.org/10.1172/JCI83496)

23 Lenard A, Daetwyler S, Betz C, Ellertsdottir E, Belting HG, Huisken J \& Affolter M. Endothelial cell self-fusion during vascular pruning. PLoS Biology 201513 e1002126. (https://doi.org/10.1371/journal. pbio.1002126)

24 Ricard N \& Simons M. When it is better to regress: dynamics of vascular pruning. PLoS Biology 201513 e1002148. (https://doi. org/10.1371/journal.pbio.1002148)

25 Hoefer IE, den Adel B \& Daemen MJAP. Biomechanical factors as triggers of vascular growth. Cardiovascular Research 201399 276-283. (https://doi.org/10.1093/cvr/cvt089)

26 Stainier DY \& Fishman MC. The zebrafish as a model system to study cardiovascular development. Trends in Cardiovascular Medicine 19944 207-212. (https://doi.org/10.1016/1050-1738(94)90036-1)

27 Sehnert AJ \& Stainier DYR. A window to the heart: can zebrafish mutants help us understand heart disease in humans? Trends in Genetics 200218 491-494. (https://doi.org/10.1016/s01689525(02)02766-x)

28 Sehnert AJ, Huq A, Weinstein BM, Walker C, Fishman M \& Stainier DYR. Cardiac troponin T is essential in sarcomere assembly and cardiac contractility. Nature Genetics 200231 106-110. (https:// doi.org/10.1038/ng875)

29 Stainier DYR, Raz E, Lawson ND, Ekker SC, Burdine RD, Eisen JS, Ingham PW, Schulte-Merker S, Yelon D, Weinstein BM, et al. Guidelines for morpholino use in zebrafish. PLoS Genetics 201713 e1007000. (https://doi.org/10.1371/journal.pgen.1007000)

This work is licensed under a Creative Common Attribution-NonCommercial 4.0 International License. ded from Bioscientifica, com at 04/26/2023 09:56:46AM 
30 Fortuna V, Pardanaud L, Brunet I, Ola R, Ristori E, Santoro MM, Nicoli S \& Eichmann A. Vascular mural cells promote noradrenergic differentiation of embryonic sympathetic neurons. Cell Reports 2015 11 1786-1796. (https://doi.org/10.1016/j.celrep.2015.05.028)

31 Rödel CJ, Otten C, Donat S, Lourenço M, Fischer D, Kuropka B, Paolini A, Freund C \& Abdelilah-Seyfried S. Blood flow suppresses vascular anomalies in a zebrafish model of cerebral cavernous malformations. Circulation Research 2019125 e43-e54. (https://doi. org/10.1161/CIRCRESAHA.119.315076)

32 Watson O, Novodvorsky P, Gray C, Rothman AMK, Lawrie A, Crossman DC, Haase A, McMahon K, Gering M, Van Eeden FJ, et al. Blood flow suppresses vascular Notch signalling via dll4 and is required for angiogenesis in response to hypoxic signalling. Cardiovascular Research 2013100 252-261. (https://doi.org/10.1093/ cvr/cvt170)

33 Serbanovic-Canic J, de Luca A, Warboys C, Ferreira PF, Luong LA, Hsiao S, Gauci I, Mahmoud M, Feng S, Souilhol C, et al. Zebrafish model for functional screening of flow-responsive genes. Arteriosclerosis, Thrombosis, and Vascular Biology 201737 130-143. (https://doi.org/10.1161/ATVBAHA.116.308502)

34 Aleström P, D’Angelo L, Midtlyng PJ, Schorderet DF, SchulteMerker S, Sohm F \& Warner S. Zebrafish: housing and husbandry recommendations. Laboratory Animals 202054 213-224. (https://doi. org/10.1177/0023677219869037)

35 Westerfield M. The Zebrafish Book: A Guide for Laboratory Use of Zebrafish (Brachydanio rerio). University of Oregon Press, 1993.

36 Kimmel CB, Ballard WW, Kimmel SR, Ullmann B \& Schilling TF. Stages of embryonic development of the zebrafish. Developmental Dynamics 1995203 253-310. (https://doi.org/10.1002/aja.1002030302)

37 Chi NC, Shaw RM, De Val S, Kang G, Jan LY, Black BL \& Stainier DYR. Foxn4 directly regulates tbx2b expression and atrioventricular canal formation. Genes and Development 200822 734-739. (https://doi. org/10.1101/gad.1629408)

38 Blum Y, Belting HG, Ellertsdottir E, Herwig L, Lüders F \& Affolter M. Complex cell rearrangements during intersegmental vessel sprouting and vessel fusion in the zebrafish embryo. Developmental Biology 2008 316 312-322. (https://doi.org/10.1016/j.ydbio.2008.01.038)

39 Renshaw SA, Loynes CA, Trushell DMI, Elworthy S, Ingham PW \& Whyte MKB. A transgenic zebrafish model of neutrophilic inflammation. Blood 2006108 3976-3978. (https://doi.org/10.1182/ blood-2006-05-024075)

40 Gray C, Loynes CA, Whyte MKB, Crossman DC, Renshaw SA \& Chico TJA. Simultaneous intravital imaging of macrophage and neutrophil behaviour during inflammation using a novel transgenic zebrafish. Thrombosis and Haemostasis 2011105 811-819. (https://doi. org/10.1160/TH10-08-0525)

41 Morsch M, Radford R, Lee A, Don EK, Badrock AP, Hall TE, Cole NJ \& Chung R. In vivo characterization of microglial engulfment of dying neurons in the zebrafish spinal cord. Frontiers in Cellular Neuroscience 20159 321. (https://doi.org/10.3389/fncel.2015.00321)

42 Hamilton N, Rutherford HA, Petts JJ, Isles HM, Weber T, Henneke M, Gärtner J, Dunning MJ \& Renshaw SA. The failure of microglia to digest developmental apoptotic cells contributes to the pathology of RNaseT2-deficient leukoencephalopathy. Glia 202068 1531-1545. (https://doi.org/10.1002/glia.23829)

43 Verduzco D \& Amatruda JF. Analysis of cell proliferation, senescence and cell death in zebrafish embryos. Methods in Cell Biology 2011101 19-38. (https://doi.org/10.1016/B978-0-12-387036-0.00002-5)

44 Zhang C, Li C, Jia X, Wang K, Tu Y, Wang R, Liu K, Lu T \& He C. In vitro and in vivo anti-inflammatory effects of polyphyllin VII through downregulating MAPK and NF- «B pathways. Molecules 201924875. (https://doi.org/10.3390/molecules24050875)

45 Kojima H, Nakatsubo N, Kikuchi K, Kawahara S, Kirino Y, Nagoshi H, Hirata Y \& Nagano T. Detection and imaging of nitric oxide with novel fluorescent indicators: diaminofluoresceins. Analytical Chemistry 1998 70 2446-2453. (https://doi.org/10.1021/ac9801723)
46 Kugler E, Plant K, Chico T \& Armitage P. Enhancement and segmentation workflow for the developing zebrafish vasculature. Journal of Imaging 20195 14. (https://doi.org/10.3390/ jimaging5010014)

47 Gonzalez R \& Woods R. Digital Image Processing. Pearson Prenctice Hall, 2018.

48 Lim J. Two-Dimensional Signal and Image Processing, pp. 469-476. Englewood Cliffs, NJ: Prentice Hall, 1990.

49 Sternberg SR. Biomedical image processing. Computer 198316 22-34. (https://doi.org/10.1109/MC.1983.1654163)

50 Burger W \& Burge M. Digital Image Processing. London: Springer, 2008. (https://doi.org/10.1007/978-1-4471-6684-9)

51 Schindelin J, Arganda-Carreras I, Frise E, Kaynig V, Longair M, Pietzsch T, Preibisch S, Rueden C, Saalfeld S, Schmid B, et al. Fiji - an Open Source platform for biological image analysis. Nature Methods 20129 676-682. (https://doi.org/10.1038/nmeth.2019)

52 Otsu N. A threshold selection method from gray-level histograms. IEEE Transactions on Systems, Man, and Cybernetics 1979 $962-66$. (https://doi.org/10.1109/TSMC.1979.4310076)

53 Kugler E, Chico T \& Armitage P. Image analysis in light sheet fluorescence microscopy images of transgenic zebrafish vascular development. In Medical Image Understanding and Analysis. MIUA 2018, pp. 343-353. Eds M Nixon, S Mahmoodi \& R Zwiggelaar. Cham: Springer, 2018. (https://doi.org/10.1007/978-3-319-95921-4_32)

54 Kugler E, Chico T \& Armitage PA. Validating segmentation of the zebrafish vasculature. In Medical Image Understanding and Analysis, pp. 270-281. Eds Y Zheng, BM Williams \& K Chen. Cham: Springer International Publishing, 2020. (https://doi.org/10.1007/978-3-03039343-4_23)

55 Kimura E, Isogai S \& Hitomi J. Integration of vascular systems between the brain and spinal cord in zebrafish. Developmental Biology 2015406 40-51. (https://doi.org/10.1016/j.ydbio.2015.07.015)

56 Goetz JG, Steed E, Ferreira RR, Roth S, Ramspacher C, Boselli F, Charvin G, Liebling M, Wyart C, Schwab Y, et al. Endothelial cilia mediate low flow sensing during zebrafish vascular development. Cell Reports 20146 799-808. (https://doi.org/10.1016/j.celrep.2014.01.032)

57 Karthik S, Djukic T, Kim JD, Zuber B, Makanya A, Odriozola A, Hlushchuk R, Filipovic N, Jin SW \& Djonov V. Synergistic interaction of sprouting and intussusceptive angiogenesis during zebrafish caudal vein plexus development. Scientific Reports 20188 9840. (https://doi. org/10.1038/s41598-018-27791-6)

58 Eltzschig HK \& Carmeliet P. Hypoxia and inflammation. New England Journal of Medicine 2011364 656-665. (https://doi.org/10.1056/ NEJMra0910283)

59 Grimes AC, Stadt HA, Shepherd IT \& Kirby ML. Solving an enigma: arterial pole development in the zebrafish heart. Developmental Biology 2006290 265-276. (https://doi.org/10.1016/j. ydbio.2005.11.042)

60 Gebala V, Collins R, Geudens I, Phng LK \& Gerhardt H. Blood flow drives lumen formation by inverse membrane blebbing during angiogenesis in vivo. Nature Cell Biology 201618 443-450. (https://doi. org/10.1038/ncb3320)

$61 \mathrm{Xu} \mathrm{J}$, Wang T, Wu Y, Jin W \& Wen Z. Microglia colonization of developing zebrafish midbrain is promoted by apoptotic neuron and lysophosphatidylcholine. Developmental Cell 201638 214-222. (https://doi.org/10.1016/j.devcel.2016.06.018)

62 Bussmann J, Wolfe SA \& Siekmann AF. Arterial-venous network formation during brain vascularization involves hemodynamic regulation of chemokine signaling. Development 2011138 1717-1726. (https://doi.org/10.1242/dev.059881)21429983.

63 Packham IM, Gray C, Heath PR, Hellewell PG, Ingham PW, Crossman DC, Milo M \& Chico TJA. Microarray profiling reveals CXCR4a is downregulated by blood flow in vivo and mediates collateral formation in zebrafish embryos. Physiological Genomics 200938 319-327. (https://doi.org/10.1152/ physiolgenomics.00049.2009) 
64 Geudens I, Coxam B, Alt S, Gebala V, Vion AC, Meier K, Rosa A $\&$ Gerhardt H. Artery-vein specification in the zebrafish trunk is pre-patterned by heterogeneous Notch activity and balanced by flowmediated fine-tuning. Development 2019146 dev181024. (https://doi. org/10.1242/dev.181024)

65 Weijts B, Gutierrez E, Saikin SK, Ablooglu AJ, Traver D, Groisman A \& Tkachenko E. Blood flow-induced Notch activation and endothelial migration enable vascular remodeling in zebrafish embryos. Nature Communications 20189 5314. (https://doi.org/10.1038/s41467-01807732-7)

66 Franco CA, Jones ML, Bernabeu MO, Vion AC, Barbacena P, Fan J, Mathivet T, Fonseca CG, Ragab A, Yamaguchi TP, et al. Non-canonical Wnt signalling modulates the endothelial shear stress flow sensor in vascular remodelling. eLife 20165 e07727. (https://doi.org/10.7554/ eLife.07727)

67 Bazmara H, Soltani M, Sefidgar M, Bazargan M, Mousavi Naeenian M \& Rahmim A. The vital role of blood flow-induced proliferation and migration in capillary network formation in a multiscale model of angiogenesis. PLoS ONE 201510 e0128878. (https://doi.org/10.1371/ journal.pone.0128878)

68 Neto F, Klaus-Bergmann A, Ong YT, Alt S, Vion AC, Szymborska A, Carvalho JR, Hollfinger I, Bartels-Klein E, Franco CA, et al. YAP and TAZ regulate adherens junction dynamics and endothelial cell distribution during vascular development. eLife 20187 e31037. (https://doi.org/10.7554/eLife.31037)

69 Kwon HB, Wang S, Helker CSM, Rasouli SJ, Maischein HM, Offermanns S, Herzog W \& Stainier DYR. In vivo modulation of endothelial polarization by apelin receptor signalling Nature Communications 20167 11805. (https://doi.org/10.1038/ ncomms11805)

70 Proulx K, Lu A \& Sumanas S. Cranial vasculature in zebrafish forms by angioblast cluster-derived angiogenesis. Developmental Biology 2010 348 34-46. (https://doi.org/10.1016/j.ydbio.2010.08.036)

71 Siekmann AF, Standley C, Fogarty KE, Wolfe SA \& Lawson ND. Chemokine signaling guides regional patterning of the first embryonic artery. Genes and Development 200923 2272-2277. (https:// doi.org/10.1101/gad.1813509)

72 Vanhollebeke B, Stone OA, Bostaille N, Cho C, Zhou Y, Maquet E, Gauquier A, Cabochette P, Fukuhara S, Mochizuki N, et al. Tip cell- specific requirement for an atypical Gpr124- and Reck-dependent Wnt/beta-catenin pathway during brain angiogenesis. eLife 20154 e06489. (https://doi.org/10.7554/eLife.06489)

73 Feng S, Bowden N, Fragiadaki M, Souilhol C, Hsiao S, Mahmoud M, Allen S, Pirri D, Ayllon BT, Akhtar S, et al. Mechanical activation of hypoxia-inducible factor $1 \alpha$ drives endothelial dysfunction at atheroprone sites. Arteriosclerosis, Thrombosis, and Vascular Biology 2017 37 2087-2101. (https://doi.org/10.1161/ATVBAHA.117.309249)

74 Mahmoud MM, Serbanovic-Canic J, Feng S, Souilhol C, Xing R, Hsiao S, Mammoto A, Chen J, Ariaans M, Francis SE, et al. Shear stress induces endothelial-to-mesenchymal transition via the transcription factor Snail. Scientific Reports 20177 3375. (https://doi.org/10.1038/ s41598-017-03532-z)

75 Novodvorsky P \& Chico TJA. The role of the transcription factor KLF2 in vascular development and disease. Progress in Molecular Biology and Translational Science 2014124 155-188. (https://doi.org/10.1016/B9780-12-386930-2.00007-0)

76 Serbanovic-Canic J, Souilhol C \& Evans PC. Shear stress makes its mark on the endothelial genome. Cardiovascular Research 2019115 1449-1451. (https://doi.org/10.1093/cvr/cvz088)

77 Souilhol C, Serbanovic-Canic J, Fragiadaki M, Chico TJ, Ridger V, Roddie H \& Evans PC. Endothelial responses to shear stress in atherosclerosis: a novel role for developmental genes. Nature Reviews: Cardiology 202017 52-63. (https://doi.org/10.1038/s41569. 019-0239-5)

78 Benz F, Wichitnaowarat V, Lehmann M, Germano RF, Mihova D, Macas J, Adams RH, Taketo MM, Plate KH, Guérit S, et al. Low wnt/ $\beta$ catenin signaling determines leaky vessels in the subfornical organ and affects water homeostasis in mice. eLife 20198 e43818. (https:// doi.org/10.7554/eLife.43818)

79 Liang D, Chang JR, Chin AJ, Smith A, Kelly C, Weinberg ES \& Ge R. The role of vascular endothelial growth factor (VEGF) in vasculogenesis, angiogenesis, and hematopoiesis in zebrafish development. Mechanisms of Development 2001108 29-43. (https://doi.org/10.1016/ s0925-4773(01)00468-3)

80 Wiley DM \& Jin SW. Bone morphogenetic protein functions as a context-dependent angiogenic cue in vertebrates. Seminars in Cell and Developmental Biology 201122 1012-1018. (https://doi.org/10.1016/j. semcdb.2011.10.005)

Received in final form 20 May 2021

Accepted 29 July 2021

Accepted Manuscript published online 29 July 2021 (c) 2020 The authors Published by Bioscientifica Ltc

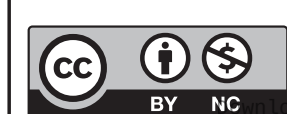

This work is licensed under a Creative Commons Attribution-NonCommercial 4.0 International License.

Led from Bioscientifica com at 04/26/2023 09:56:46AM 